\title{
Development of a Methodology for Inferface Boundary Selection in the Multiscale Road Tunnel Fire Simulations
}

\author{
Ali Haghighat* (D), Fire Life Safety, Tunnel Ventilation Group, AECOM, 300
} Lakeside Drive, Suite 400, Oakland, CA 94612, USA

Kray Luxbacher, Department of Mining and Minerals Engineering, Virginia Tech, 106 Holden Hall, 445 Old Turner Street, Blacksburg, VA 24061, USA

Brian Y. Lattimer, JENSEN HUGHES, 2270 Kraft Drive, Suite 1260, Blacksburg, VA 24060, USA

Received: 14 August 2017/Accepted: 18 April 2018

\begin{abstract}
The simulation of large complex dynamical systems such as a fire in road tunnels is necessary but costly. Therefore, there is a crucial need to design efficient models. Coupling of computational fluid dynamics (CFD) models and 1D network modeling simulations of a fire event, a multiscale method, can be a useful tool to increase the computational efficiency while the accuracy of simulations is maintained. The boundary between a CFD model (near field) and a 1D model (far field) plays a key role in the accuracy of simulations of large systems. The research presented in this paper develops a novel methodology to select the interface boundary between the 3D CFD model and a 1D model in the multiscale simulation of vehicle fire events in a tunnel. The development of the methodology is based on the physics of the fluid structure, turbulent kinetic energy of the dynamical system, and the vortex dynamics. The methodology was applied to a tunnel with $73.73 \mathrm{~m}^{2}$ cross section and $960 \mathrm{~m}$ in length. Three different vehicle fire scenarios were investigated based on two different heat reslease rates $(10 \mathrm{MW}$ and $30 \mathrm{MW})$ and two different inlet velocities $(1.5 \mathrm{~m} / \mathrm{s}$ and $5 \mathrm{~m} / \mathrm{s}$ ). all parameters upstream and downstream of the fire source in all scenarios were investigated at $\mathrm{t}=900 \mathrm{~s}$. The effect of changes in heat release rate (HRR) and air velocity on the selection of an interface boundary was investigated. The ratio between maximum longitudinal and transversal velocities was within a range of 10 to 20 in the quasi-1D region downstream of the fire source. The selected downstream interface boundary was $12 \mathrm{D}_{\mathrm{h}} \mathrm{m}$ downstream of the fire for the simulations. The upstream interface boundary was selected at $0.5 \mathrm{D}_{\mathrm{h}} \mathrm{m}$ upstream the tip of the object when the velocity was greater than equal to the $\mathrm{V}_{\mathrm{c}}$. In the simulations with backlayering $\left(\mathrm{V}<\mathrm{V}_{\mathrm{c}}\right)$, the interface boundary was selected $10 \mathrm{~m}$ further from the tip of the backlayering $\left(1.2 \mathrm{D}_{\mathrm{h}}\right)$. An indirect coupling strategy was utilized to couple CFD models to $1 \mathrm{D}$ models at the selected interface boundary; then, the coupled models results were compared to the full CFD model results. The calculated error between
\end{abstract}

\footnotetext{
* Correspondence should be addressed to: Ali Haghighat, E-mail: ali.haghighat@aecom.com
} 
CFD and coupled models for mean temperature and velocity at different cross sections were calculated at less than $5 \%$. The findings were used to recommend a modification to the selection of interface boundary in multiscale fire simulations in the road tunnels and more complex geometries such as mines.

Keywords: Computational fluid dynamics (CFD), Interface boundary, Transportation tunnel fire, Multiscale methodology

\section{List of symbols}

$V_{c} \quad$ Critical velocity $(\mathrm{m} / \mathrm{s})$

$K_{1} \quad$ Froude number factor (1)

$K_{g} \quad$ Grade factor (1)

$g \quad$ Acceleration caused by gravity $\left(\mathrm{m} / \mathrm{s}^{2}\right)$

$H \quad$ The height of duct or tunnel at the fire site (m)

$Q \quad$ Heat fire is adding directly to air at the fire site $(\mathrm{kW})$

$\rho \quad$ The average density of the approach (upstream) air $\left(\mathrm{kg} / \mathrm{m}^{3}\right)$

$C_{p} \quad$ Specific heat of air $(\mathrm{kJ} / \mathrm{kgK})$

$A \quad$ The area perpendicular to the flow $\left(\mathrm{m}^{2}\right)$

$T_{f} \quad$ The average temperature of the fire site gases (K)

$\mathrm{T} \quad$ The temperature of the approach air $(\mathrm{K})$

$\mathrm{D}_{\mathrm{h}} \quad$ Hydraulic diameter $(\mathrm{m})$

$\Delta H_{\mathrm{T}} \quad$ Heat of combustion $(\mathrm{kJ} / \mathrm{kg})$

$\mathrm{Y}_{\mathrm{CO}} \quad \mathrm{CO}$ yield $(\mathrm{kg} / \mathrm{kg})$

$\mathrm{Y}_{\mathrm{CO}_{2}} \quad \mathrm{CO}_{2}$ yield $(\mathrm{kg} / \mathrm{kg})$

$\mathrm{Y}_{\text {Soot }}$ Soot yield $(\mathrm{kg} / \mathrm{kg})$

D* The characteristic length scale

$\dot{Q} \quad$ The heat release rate of the fire $(\mathrm{kW})$

$\rho_{\infty} \quad$ Air density $\left(\mathrm{kg} / \mathrm{m}^{3}\right)$

$T_{\infty} \quad$ Ambient air temperature (K)

$\mathrm{u} \quad \mathrm{u}$ velocity $(\mathrm{m} / \mathrm{s})$

v v velocity $(\mathrm{m} / \mathrm{s})$

W W velocity $(\mathrm{m} / \mathrm{s})$

TKE Turbulent kinetic energy $(\mathrm{m} / \mathrm{s})^{2}$

$\mathrm{IB}_{\mathrm{Up}} \quad$ Upstream interface boundary

$\mathrm{IB}_{\text {Down }}$ Downstream interface boundary

$\mathrm{C}_{\mathrm{v}} \quad$ Coupling variable

\section{Introduction}

The simulation cost of a complex dynamical system is an important consideration in engineering design and analysis, especially in fire protection engineering. One of the most common numerical approaches is computational fluid dynamics (CFD). The CFD numerical analysis is often utilized for precise studies of fluid behavior in underground space environments [3, 14, 41, 52]. This kind of numerical analysis is common to be utilized near fire field. For large domains such as road tunnel environments, network modeling software, one-dimensional (1D) simulations, can be a useful tool for fire analysis at the far field, because of low computational requirements. However, the $1 \mathrm{D}$ modeling approach cannot analyze the characteristics of complex flow regions encountered close to the fire source. Therefore, the multiscale methodology is a useful approach to couple a CFD solver with a 1D 
model to keep the accuracy and increase the computational efficiency. This approach has been used extensively in different fields. This technique was applied successfully in environmental engineering, mechanical engineering, and bio engineering $[9,29,39,50]$. The advantage of proposed method is the reduction in the overall computation time.

Coupling methods have been used in the simulation of airflow and fire in the transportation tunnels. Colella et al. coupled CFD and 1D models of a tunnel ventilation system to decrease the ventilation simulation cost in transportation tunnels. This approach allows for the complexity of full CFD models of flow in tunnels and the inaccuracies of simplified 1D models can be avoided [10]. Colella et al. also worked on simulation of tunnel ventilation flows during fires. In that study, a simple 1D network approach was utilized to simulate tunnel regions where the flow structure is 1D (far field), and for flow conditions require three-dimensional (3D) resolution (near field), CFD was utilized. Different fire sizes ranging from $10 \mathrm{MW}$ to $100 \mathrm{MW}$ were investigated with a variable number of velocities. Both direct and indirect coupling strategies in steady state condition were utilized and compared. Several multiscale simulations were run to identify the interface boundary limit which is referred to as the interface boundary independence study. In that study, the CFD domain was gradually increased while the $1 \mathrm{D}$ domain was gradually decreased. Then the associated average error was calculated with the following norm:

$$
\varepsilon_{\varphi}=\frac{\sum_{j=1}^{N}\left|\vartheta_{j, C F D}-\vartheta_{j, m s}\right|}{N \overline{\vartheta_{C F D}}}
$$

where $\vartheta_{j, C F D}$ and $\vartheta_{j, m s}$ are the values calculated in each grid point $\mathrm{j}$ belonging to the reference section of interest and $\overline{\vartheta_{C F D}}$ is the averaged predicted by the full CFD simulation. The subscripts $C F D$ and $m s$ are referred to the full CFD and multiscale simulation results. The summation over $\mathrm{j}$ is extended to all the $\mathrm{N}$ grid points belonging to the specific section of the domain under study. The average of parameters, such as average temperature and average longitudinal velocity, were used for calculation of errors. It was recommended that the location of downstream interface boundary should be at a distance from the fire larger than 13 times the hydraulic diameter $\left(D_{h}\right)$ when the velocity is close to the critical velocity [12]. The recommended ratio between hydraulic diameter and the distance from the fire to the downstream interface boundary provided good agreement with the same ratio which was recommended by Van Maele for different fire scenarios in a small scale tunnel [45]. In addition, the multiscale approach was utilized to study the transient flow interaction between a growing fire and a ramping-up ventilation scenarios. The time required to reach critical velocity conditions to remove backlayering was investigated in that study. The results from multiscale approach showed that the required computing time decreased by 40 times without any loss of accuracy compare to the full CFD model [13]. In previous research studies, several multiscale simuations were simulated in order to determine the interface boundaries [12]. The lowest average error between CFD and coupled models at 
different cross sections was the criterion for selection of the interface boundary. Therfore, an iterative method was utilized to reduce the boundary, and to compare the coupled model with the full-order CFD model across the entire domain. However, in this study, a novel methodology was developed based on the fundamental physics of fluid, including the physics of the fluid structure, turbulent kinetic energy (TKE), and the vortex dynamics to determine the interface boundaries. Since this methodology considers the physical mechanism driving flow it can easily be applied to different underground spaces with more complex geometry.

In addition, in previous research studies, the Reynolds-Averaged Navier-Stokes (RANS) equations were used for simulation of the turbulent fluctuations of CFD results. This approach, which has been largely used to simulate fire and smoke propagation $[8,12,13,45,47,50,51]$, can provide results for mean quantities with acceptable accuracy at moderate cost. However, this approach has its own limitations. Van Maele and Merci applied and compared both RANS and Large Eddy Simulation (LES) approaches for well-ventilated horizontal tunnel fires. The measured critical velocity in the experiment was compared to LES and RANS simulations, and the temperature contours of the LES simulations for $30 \mathrm{~kW}$ fire showed better agreement with the experimental results than the RANS simulations results. Moreover, the turbulent thermal diffusion in the LES simulation showed better agreement than in the RANS simulations due to the large-scale unsteadiness in the LES [45]. LES bears less modeling uncertainties such as wakes of bluff bodies' structure in comparison with RANS, because the flow behavior is dominated by large-scale anisotropic vortical structures [17]. Although RANS simulations have lower computation cost, by a factor of 10 to 100 [8], LES was preferred for this study for the reasons just described.

This research focuses on the development of a methodology to determine the interface boundary region upstream and downstream of a fire source in the transportation tunnels to decompose the domain into 3D and $1 \mathrm{D}$ domains via detailed fluid dynamics analysis. Consistent with the data from previous research studies, the interface boundary should be located in the regions where the flow structure is 1D [10-12, 45]. In order to determine the interface boundary, it is necessary to find the region where the flow-field is quasi-1D, meaning that the streamwise component of the fluid dominates the flow-field [13]. On the other hand, the continuity of the following quantities at the interface boundaries ( $i$ and $j$, as shown in Fig. 1) should also be met [15].

$$
\text { Area } A\left(a^{-}\right)=A\left(a^{+}\right)
$$

Mean pressure $p\left(a^{-}\right)=p\left(a^{+}\right)$

Mean velocity $\bar{v}\left(a^{-}\right)=\bar{v}\left(a^{+}\right)$

Mean Temperature $\bar{T}\left(a^{-}\right)=\bar{T}\left(a^{+}\right)$ 


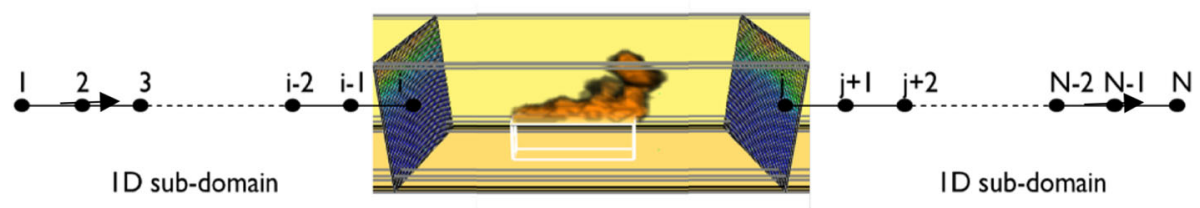

3D sub-domain

\section{Figure 1. Decomposition of the global domain into 1D and 3D sub- domains (after [ 112$]$ ).}

Therefore, since the mean information of fluid (mean velocity, mean temperature, mean pressure) are transferred at the 1D-3D interface in both directions, all the node values of the $3 \mathrm{D}$ model at the interface should be almost uniform and close to the mean values. Under these circumstances, the single value (mean value) of the 3D model at the interface boundary can be the precise representation of all the nodes in that cross section of a dynamic system. Therefore, a detailed fluid dynamics study was conducted to investigate the distribution and behavior of the longitudinal velocity component (u-velocity) and transversal velocity components (v- and w-velocities) of all nodes at different cross sections. In order to determine the quasi-1D flow structure region, there is a need to investigate the tendency of fluid particles to rotate in the system, the physics of the vortex dynamics, and also the intensity of turbulence of the system. Due to this, the mean vorticity along the $\mathrm{X}, \mathrm{Y}$, and $\mathrm{Z}$ axes and the mean turbulent kinetic energy at different cross sections of the tunnel were analyzed.

The computational fluid dynamics software Fire Dynamics Simulator (FDS), Version 6.0 was used to determine the regions where the flow structure is $3 \mathrm{D}$ versus quasi-1D. In previous research studies it was evident that the direct multiscale fire modelling is achievable by using FDS v.6.0 and Heating, Ventilation and Air Conditioning (HVAC) feature. A significant improvement in reduction of computational time was achieved when the combination of multiple meshes and multiscale fire modelling was applied in simulations [1, 49]. The FDS core algorithm is an explicit predictor-corrector scheme, with second order accuracy in space and time. Turbulence in this software is modeled via (LES) [36]. LES has been used extensively for the simulation of the fire in different research areas such as fire plume studies, flame height studies, plume temperature, mine fires, and etc. [17, $19,20,22,25,32,33,35,53]$. The formulation of the equations and the numerical algorithm are described elaborately in the FDS technical reference guide to which we refer the reader [36]. Although FDS version 6.0 was utilized in this research study, There has been significant changes from FDS 6.0, to 6.6 (current version) in order to improve the robustness and accuracy of the simulations. The improvements to the robustness and accuracy of the simulation influence the simulation cost (CPU time and memory usage). The parallel processing was integerated to the the new version of FDS in order to decrease the simulation cost. Therefore, the new versions can affect the simulations' time and results' accuracy significantly. 
For the road tunnel fire scenarios two different velocities and two different heat release rates (HRR) were utilized to investigate the effect of HRR and velocity changes on the selection of 1D-3D interface boundary. The interface boundary regions were determined according to study results. Then, the 1D models were simulated via VentFIRE ${ }^{\text {TM }}$ in order to couple to the full CFD simulations. VentFIRE ${ }^{\text {TM }}$ is a module of Ventsim Visual program which the transport of the smoke and heat are simulated via a discrete sub-cell transport and node mixing method [48]. The indirect coupling strategy was utilized for coupling of CFD models to 1D models; the coupled results were compared to the full CFD and 1D models. In general, there are two different approaches to couple 3D models to 1D models which refered as direct and indirect coupling approaches. In direct coupling methodology, the 1D models and 3D models are simulated and run iteratively together while in indirect coupling methodology the 1D and 3D simulations would be simulated and run separately. For detailed explaination of the direct and indirect coupling methodology, we refer the reader [12]. Ultimately, a methodology was developed and recommended for selection of the interface boundary for multiscale simulation of fire in road tunnels.

\section{Simulation Consideration}

Three computational fluid dynamics (CFD) scenarios were considered to investigate the significant parameters for the selection of interface boundaries for the development of a multiscale methodology applied to road tunnel fire simulations. FDS was utilized to predict the conditions that develop due to the $10 \mathrm{MW}$ and $30 \mathrm{MW}$ vehicle fires in a 2 lane road tunnel. A two lane standard cross section of a road tunnel [34], is considered in this study. The height of tunnel was set to $7.7 \mathrm{~m}$. Although pedestrians are not permitted in road tunnels, the sidewalks are required and recommended to be greater than or equal to $0.7 \mathrm{~m}$ [24]. Therefore, two $0.96 \mathrm{~m}$ sidewalks were considered in the geometry of the road tunnels. The thickness of the walls were set to $0.24 \mathrm{~m}$. The length, the width, and the height of the whole tunnel was $960 \mathrm{~m}, 9.6 \mathrm{~m}$, and $7.7 \mathrm{~m}$, respectively. The detailed tunnel geometry dimensions used in the simulations are shown in Fig. 2.

Previous studies have shown that smoke generation is affected by different parameters, including HRR, ventilation, and the dimension of the obstruction (National Cooperative Highway Research Program (NCHRP) Synthesis 415 [37]). Babrauskas and Peacock discussed the HRR as the single most important variable in fire hazard [2], while the other important parameter in terms of smoke propagation is ventilation [6].

Studies examining backlayering and critical velocity show that the critical velocity varies from $2.5 \mathrm{~m} / \mathrm{s}$ to $3 \mathrm{~m} / \mathrm{s}$ for the $10 \mathrm{MW}$ to $100 \mathrm{MW}$ fires [26, 28, 40, 46, 53]. Critical velocity varies based on the hydraulic diameter of a tunnel. Thus, the critical velocity was calculated for $10 \mathrm{MW}$ and $30 \mathrm{MW}$ vehicle fires in the simulated road tunnel in this study with the following equations: 


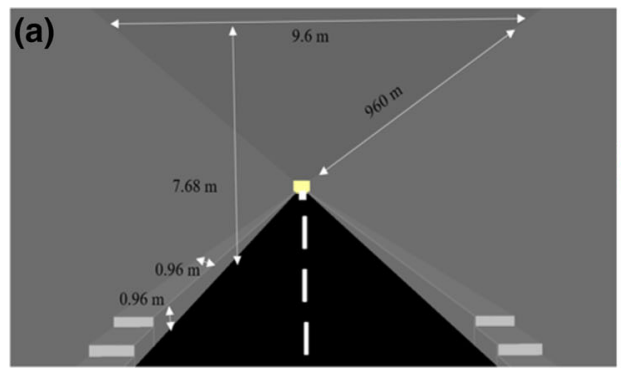

(b)

\section{Figure 2. Two lane transportation tunnel dimensions and layout (a)} funnel dimension (b) isometric view of the computational domain.

$$
\begin{aligned}
& V_{c}=K_{1} K_{g}\left[\frac{g H Q}{\rho C_{p} A T_{f}}\right]^{1 / 3} \\
& T_{f}=\left[\frac{Q}{\rho C_{p} A V_{c}}\right]+T
\end{aligned}
$$

where $V_{c}$ is critical velocity in $(\mathrm{m} / \mathrm{s}), K_{1}$ is Froude number factor $1, K_{g}$ is grade factor (1), $\mathrm{g}$ is acceleration caused by gravity $\left(\mathrm{m} / \mathrm{s}^{2}\right), H$ is the height of duct or tunnel at the fire site $(\mathrm{m}), Q$ is heat fire is adding directly to air at the fire site $(\mathrm{kW}), \rho$ is the average density of the approach (upstream) air $\left(\mathrm{kg} / \mathrm{m}^{3}\right), C_{p}$ is specific heat of air $(\mathrm{kJ} / \mathrm{kg} \mathrm{K}), A$ is the area perpendicular to the flow $\left(\mathrm{m}^{2}\right), T_{f}$ is the average temperature of the fire site gases $(\mathrm{K})$, and $\mathrm{T}$ is the temperature of the approach air in (K) (National Fire Protection Association (NFPA), "NFPA ${ }^{\circledR} 502$ [38]. The calculated hydraulic diameter for the two lane road tunnel was $8.53 \mathrm{~m}$. The critical velocity varied from $2.6 \mathrm{~m} / \mathrm{s}$ to $3.7 \mathrm{~m} / \mathrm{s}$ for $10 \mathrm{MW}$ and $30 \mathrm{MW}$ fires in the associated tunnel. The effect of various air velocities on back layering phenomenon in the simulated road tunnels is shown in Fig. 3.

According to $\mathrm{NFPA}^{\circledR} 502$, the maximum tolerable air velocity under emergency conditions for motorists is $11 \mathrm{~m} / \mathrm{s}$. Also, the minimum air velocity should be enough to prevent the backlayering (National Fire Protection Association (NFPA), "NFPA ${ }^{\circledR} 502$ [38]. In this study, a velocity less than critical velocity $\left(1.5 \mathrm{~m} / \mathrm{s}<\mathrm{V}_{\mathrm{c}}\right)$ was selected for investigation of interface boundary region where the smoke and hot gases propagates to the upstream and the downstream of the fire. Moreover, a velocity greater than critical velocity $\left(5 \mathrm{~m} / \mathrm{s} \geq \mathrm{V}_{\mathrm{c}}\right)$ was selected for investigation of interface boundaries when the smoke propagates just downstream of the fire. The main purpose of selected velocities was, to investigate the effect of air velocity changes on the interface boundaries determination. Two different HRR (10 MW, $30 \mathrm{MW}$ ) were considered as the peak heat release rates for the van and the bus fires respectively (National Fire Protection Association (NFPA), "NFPA ${ }^{\circledR} 502$ [38]. The t-squared approach was used for the growth of 


\section{(a)}

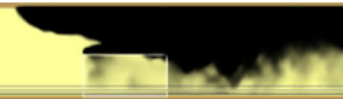

(b)

(c)

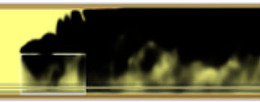

(d)

(e)

(f)

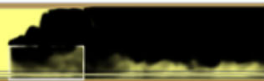

\section{Figure 3. The effect of different velocities on smoke propagation of $10 \mathrm{MW}$ and $30 \mathrm{MW}$ vehicle fires in the road tunnel at $t=100 \mathrm{~s}$ (a) $10 \mathrm{MW}, 1.5 \mathrm{~m} / \mathrm{s}$, (b) $10 \mathrm{MW}, 2.8 \mathrm{~m} / \mathrm{s}$, (c) $10 \mathrm{MW}, 5 \mathrm{~m} / \mathrm{s}$, (d) $30 \mathrm{MW}, 1.5 \mathrm{~m} / \mathrm{s}$, (e) $30 \mathrm{MW}, 3.7 \mathrm{~m} / \mathrm{s}$, (f) $30 \mathrm{MW}, 5 \mathrm{~m} / \mathrm{s}$.}

the vehicle fires. The time to reach maximum HRR ( $\left.t_{\max }\right)$ for van fire and bus fire were recommended to be $5 \mathrm{~min}$ and $10 \mathrm{~min}$, respectively [27]. However, because of the simulation cost, the $t_{\max }$ was set to $1 \mathrm{~min}$. Since the focus of the research in this paper is to develop a methodology for selection of interface boundaries for fire simulations in a road tunnel, the decay time period for vehicle fires was not considered in the study. Flexible polyurethane foams were utilized for vehicle fire simulation in the tunnels. The heat of combustion and the yield of fire products were set as shown in Table 1 [43].

Three different scenarios, as shown in Table 2, were simulated for investigation of different parameters in order to determine the interface boundaries. Then, the indirect coupling strategy was utilized for coupling of CFD models to 1D models. The 1D models were simulated using VentFIRE. All the vehicle fires were set in the middle of the road tunnels. A bus with dimensions of $12 \times 2.6 \times 3.6 \mathrm{~m}^{3}$ as the length, width, and height, respectively, was considered as the fire object for simulations.

\section{Geometry, Initial and Boundary Conditions}

The thermal and the physical parameters of the tunnel wall concrete, including, density, thermal conductivity, and specific heat were set to $2400 \mathrm{~kg} / \mathrm{m}^{3}, 1 \mathrm{~W} / \mathrm{m}{ }^{\circ} \mathrm{C}$, and $0.96 \mathrm{~kJ} / \mathrm{kg}{ }^{\circ} \mathrm{C}$, respectively [4]. The rock types in the concrete were assumed to be limestone, sandstone, and chert, and it was assumed that the sand and aggregate were from the same rock type at an early age. The thermal diffusivity of concrete was set to $0.77 \mathrm{~mm}^{2} / \mathrm{s}[30]$.

The physical and the thermal characteristics of asphalt depend on the air voids in the dry or wet asphalts. A 5\% air voids content was assumed for consideration of different parameters. The physical and the thermal parameters of the dry pavement asphalt, including density, thermal conductivity, and specific heat capacity were set to $2372 \mathrm{~kg} / \mathrm{m}^{3}, 1.16 \mathrm{~W} / \mathrm{m}^{\circ} \mathrm{C}$, and $0.9637 \mathrm{~kJ} / \mathrm{kg}{ }^{\circ} \mathrm{C}$, respectively [21]. The no-slip boundary condition was considered for all walls and the objects in the domain. In this study, the jet fans used for tunnel ventilation were assumed to be far away from the fire source. Therefore, a fixed air flow was set at the inlet of the computational domains. The cell size near the fire source plays a key role in the accuracy and stability of the numerical computation. A sufficiently fine grid can 


\section{Table 1 \\ Heat of Combustion, $\mathrm{CO}, \mathrm{CO}_{2}$, and Soot Yields of Vehicle Fire Events Used in Simulation}

\begin{tabular}{lcccc}
\hline Material & $\Delta H_{\mathrm{T}}(\mathrm{kJ} / \mathrm{kg})$ & $\mathrm{Y}_{\mathrm{CO}_{2}}(\mathrm{~kg} / \mathrm{kg})$ & $\mathrm{Y}_{\mathrm{CO}}(\mathrm{kg} / \mathrm{kg})$ & $\mathrm{Y}_{\text {Soot }}(\mathrm{kg} / \mathrm{kg})$ \\
\hline Polyurethane & 25,300 & 1.5325 & 0.02775 & 0.1875 \\
\hline
\end{tabular}

\section{Table 2}

CFD Simulations According to Different Factors

\begin{tabular}{lccl}
\hline Scenarios & Velocity $(\mathrm{m} / \mathrm{s})$ & HRR $(\mathrm{MW})$ & Tunnel dimension $\left(\mathrm{m}^{2}\right)$ \\
\hline scenario 1 & 5 & 10 & 2 lanes $(73.7)$ \\
scenario 2 & 5 & 30 & 2 lanes (73.7) \\
scenario 3 & 1.5 & 10 & 2 lanes (73.7) \\
\hline
\end{tabular}

be achieved when the grid size is $\leq 0.1 D^{*}[35]$, where $D^{*}$ is representative of the characteristic length scale which corresponds to the total heat release rate of a fire plume $[5,53]$. The $\mathrm{D}^{*}$ is defined by

$$
D *=\left(\frac{\dot{Q}}{\rho_{\infty} C_{p} T_{\infty} \sqrt{g}}\right)^{2 / 5}
$$

where $\dot{\mathrm{Q}}, \rho_{\infty}, C_{p}, T_{\infty}$, and $g$ are the heat release rate of the fire in $\mathrm{kW}$, air density $\left(\sim 1.2 \mathrm{~kg} / \mathrm{m}^{3}\right)$, air thermal capacity $(\sim 1 \mathrm{~kJ} / \mathrm{kg} \mathrm{K})$, ambient air temperature $(\sim 293 \mathrm{~K})$, and gravitational acceleration $(\sim 9.81 \mathrm{~m} / \mathrm{s})$ respectively.

The heat release rates in this study were $10 \mathrm{MW}$ and $30 \mathrm{MW}$. Therefore, a grid size of $24 \mathrm{~cm}$ was considered for the numerical analysis. In all simulations, the ambient air temperature, ambient air density, and air viscosity at ambient temperature were set at $20^{\circ} \mathrm{C}, 1.196 \mathrm{~kg} / \mathrm{m}^{3}$, and $1.79 \mathrm{e}-05 \mathrm{~kg} / \mathrm{m} / \mathrm{s}$ respectively. The simulation of vehicle fires of all scenarios at $\mathrm{t}=900 \mathrm{~s}$ is shown in Fig. 4.

\section{Resulfs and Discussion}

In order to determine the region where the flow structure behaves in a quasi-1D fashion, there is a need to investigate the longitudinal (u-velocity) and the transversal velocity components ( $\mathrm{v}$ - and $\mathrm{w}$-velocities), vorticities along different axes (X, Y, and $\mathrm{Z}$ ), and the turbulent kinetic energy at each node in $3 \mathrm{D}$ CFD models. All parameters were calculated every $5 \mathrm{~m}$ upwind and downwind from the fire source. The zero line represents the cross section of the tunnel at the center of the fire source. According to Fig. 4c, the upwind transport of the smoke (backlayering) occurred in scenario 3 because the air velocity in this model, was less than the critical velocity. However, just the downwind transport of smoke was observed in scenarios 1 and 2, as shown in Fig. 4a, b. It was observed that the 
(a)

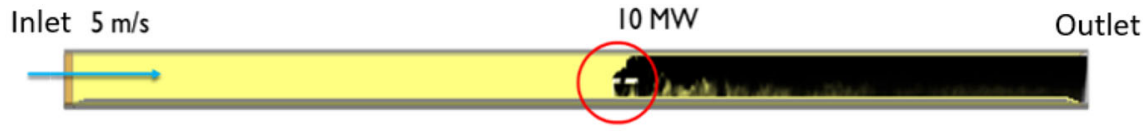

(b)

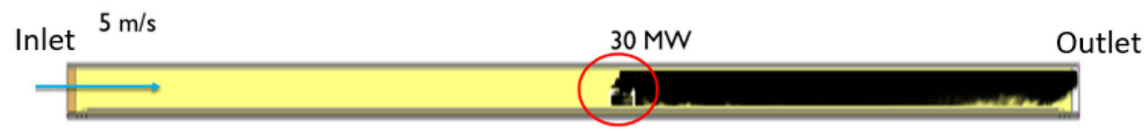

(c)

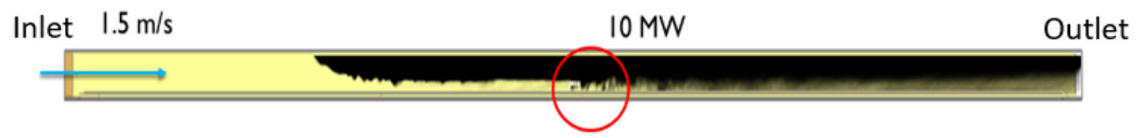

Figure 4. Vehicle fire and the smoke transport in the road tunnel at $t=900$ s for all scenarios: (a) scenario 1 , (b) scenario 2, (c) scenario 3.

backlayering did not advance significantly along the longitudinal axis after $900 \mathrm{~s}$ in scenario 3 and after that, the steady-state flow condition in the tunnel was reached. Therefore, $\mathrm{t}=900 \mathrm{~s}$ was selected to investigate all parameters upwind and downwind of the fire source in scenarios 1,2, and 3 .

\subsection{Longitudinal and Transversal Velocity Components Analysis}

The region where the flow structure is quasi-1D is the region where the domain can be split into distinct 3D and 1D sub-domains. In that region, the streamwise component of the velocity dominates the fluid structure. Therefore, detailed longitudinal and transversal velocity components analysis were conducted in order to determine the region where the influence of transversal velocity components on the fluid structure was inconsequential. The normality and distribution of the longitudinal velocity $(\mathrm{u})$ and the transversal velocities (lateral (v-velocity) and vertical (w-velocity)) of all nodes at different cross sections of the tunnel upstream and downstream of the fire source at $\mathrm{t}=900 \mathrm{~s}$ for model 1 were calculated as shown in Figs. 5, 6, and 7, respectively. All distances are from the center line of the fire.

In Fig. 5 it is evident that the longitudinal velocity (u-velocity) of all nodes along the height of the tunnel at each cross section was more normally distributed at a greater distance from the fire source (Fig. 5a, f, e), and up to $10 \mathrm{~m}$ upstream of the fire (Fig. 5b). The longitudinal velocity of all nodes at each cross section was not distributed normally up to $100 \mathrm{~m}$ downstream of the fire (Fig. 5e). According to the box-and whisker plots in Fig. 5, it is noteworthy that the dispersion of the longitudinal velocity values at cross sections increased closer to the fire source as shown in Fig. 5c, d. Due to the presence of the burning object (vehicle fire) at the middle of the tunnel and the upwind transport of smoke downstream of the fire, the dynamic flow field near the fire (from $10 \mathrm{~m}$ upstream of the fire source to $100 \mathrm{~m}$ downstream of the fire source) was not quasi-1D. This indicates that this region requires $3 \mathrm{D}$ simulation.

The distribution of transversal velocity components (v- and w-velocities) were similar to the distribution of longitudinal velocity components, as shown in 

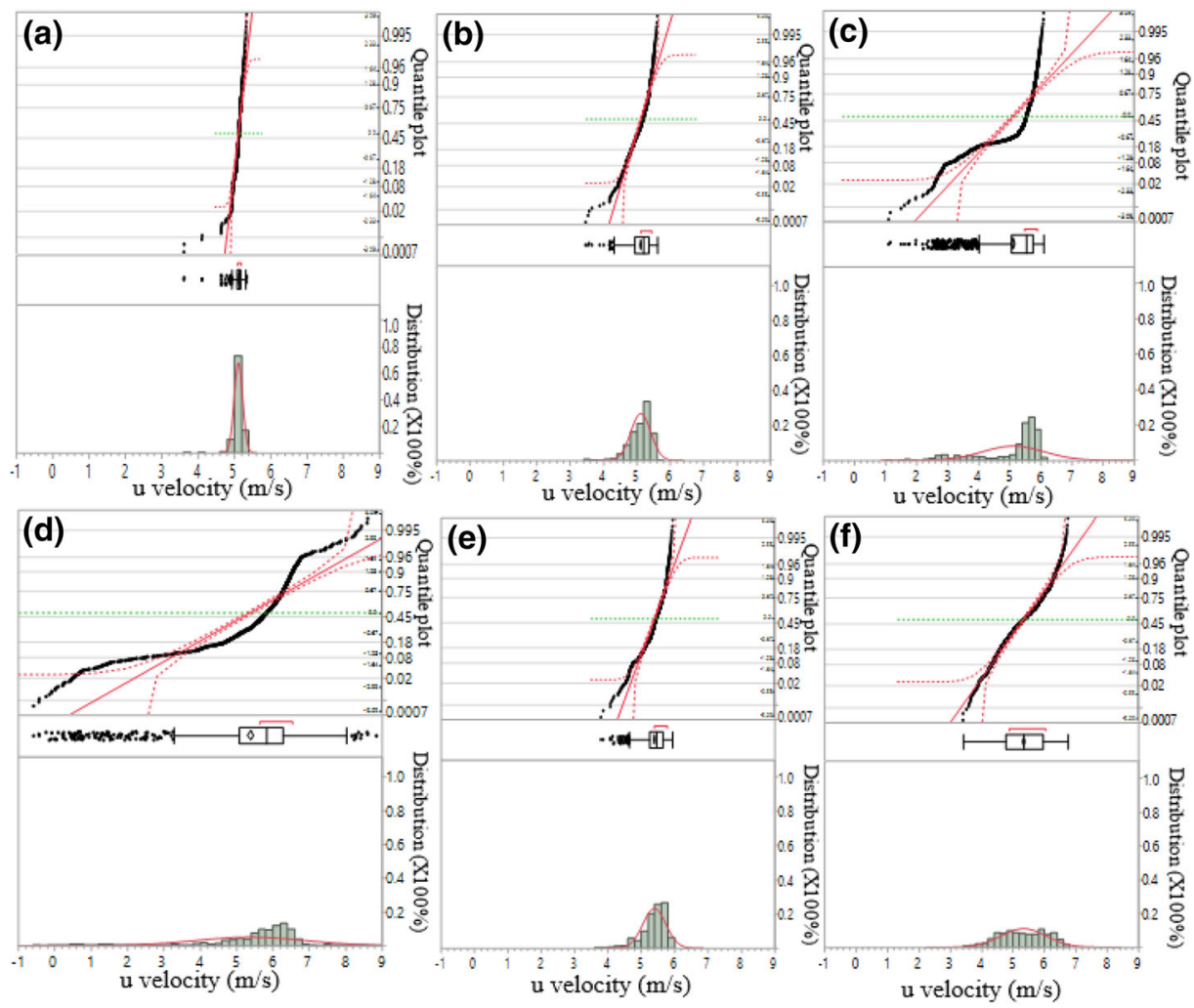

\section{Figure 5. Normal quantile plots, box-and-whisker plots, and distributions of $u$ velocity at different cross sections of the funnel at $t=900 \mathrm{~s}$ in scenario 1 at: (a) $430 \mathrm{~m}$ upstream, (b) $10 \mathrm{~m}$ upstream, (c) $7 \mathrm{~m}$ upstream, (d) $10 \mathrm{~m}$ downstream, (e) $100 \mathrm{~m}$ downstream, (f) 430 downstream.}

Figs. 6 and 7. The transversal velocities were not distributed normally near fire field (10 $\mathrm{m}$ upstream of the fire to $100 \mathrm{~m}$ downstream) while the normal distribution was observed at the far field regions (from the inlet to $10 \mathrm{~m}$ upstream and from $100 \mathrm{~m}$ downstream to the outlet). In addition, the variation and dispersion of transversal velocities of all nodes along the height of the tunnel at different cross sections increased by getting close to the fire source. Therefore, it was evident that the domination of transversal velocity components ( $v$ - and w-velocities) on the fluid field decreased by getting further away from the near fire region.

In our indirect coupling strategy, the characteristic point of 3D fire field (near fire field) (ex: mass flow rate across the boundaries, the total pressure drop across the boundaries, and the mean temperature at the boundaries) are used as the boundary condition for the 1D model [12]. The transfer of mean values of velocity, pressure, and temperature are required for the adoption of indirect coupling strategies. Therefore, a cross section at which all node values of the 3D model are 

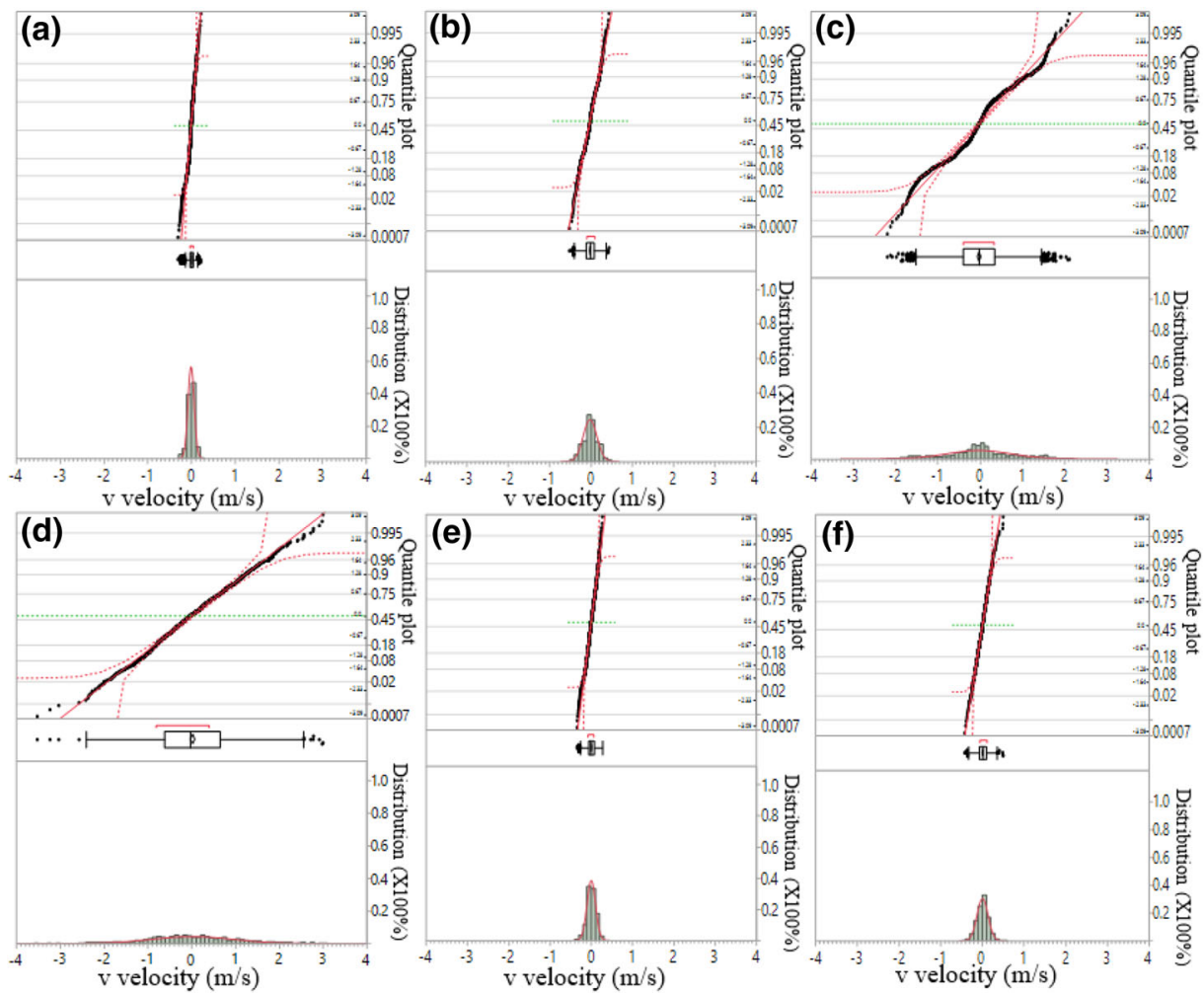

\section{Figure 6. Normal quantile plot, box-and-whisker plots, and distributions of $\mathrm{v}$ velocity at different cross sections of the tunnel at $t=900 \mathrm{~s}$ in scenario 1 at: (a) $430 \mathrm{~m}$ upstream, (b) $10 \mathrm{~m}$ upstream, (c) $7 \mathrm{~m}$ upstream, (d) $10 \mathrm{~m}$ downstream, (e) $100 \mathrm{~m}$ downstream, (f) 430 downstream.}

nearly uniform and close to the mean values can be selected as the suitable boundary for decomposing the global domain into 3D and 1D sub-domains.

Hence, the standard deviation of velocity components (longitudinal and transversal velocity components) was calculated along the height of the tunnel at different cross sections in steady state condition in order to analyze the dispersion of the velocity components at different cross sections of the tunnel. The standard deviation of the longitudinal and transversal velocities of all nodes at $t=900$ along the height of the tunnel at different cross sections of the tunnel in scenario 1 are shown in Fig. 8.

The standard deviation of the longitudinal and the transversal velocities was calculated less than 0.2 from the inlet to $10 \mathrm{~m}$ upstream of the fire source. After that point, it increased dramatically up to 1.6 at the centerline of the fire source. The highest dispersion of the longitudinal velocity of all nodes was calculated at the centerline of the vehicle fire. The reason lies in the sudden contraction of the 

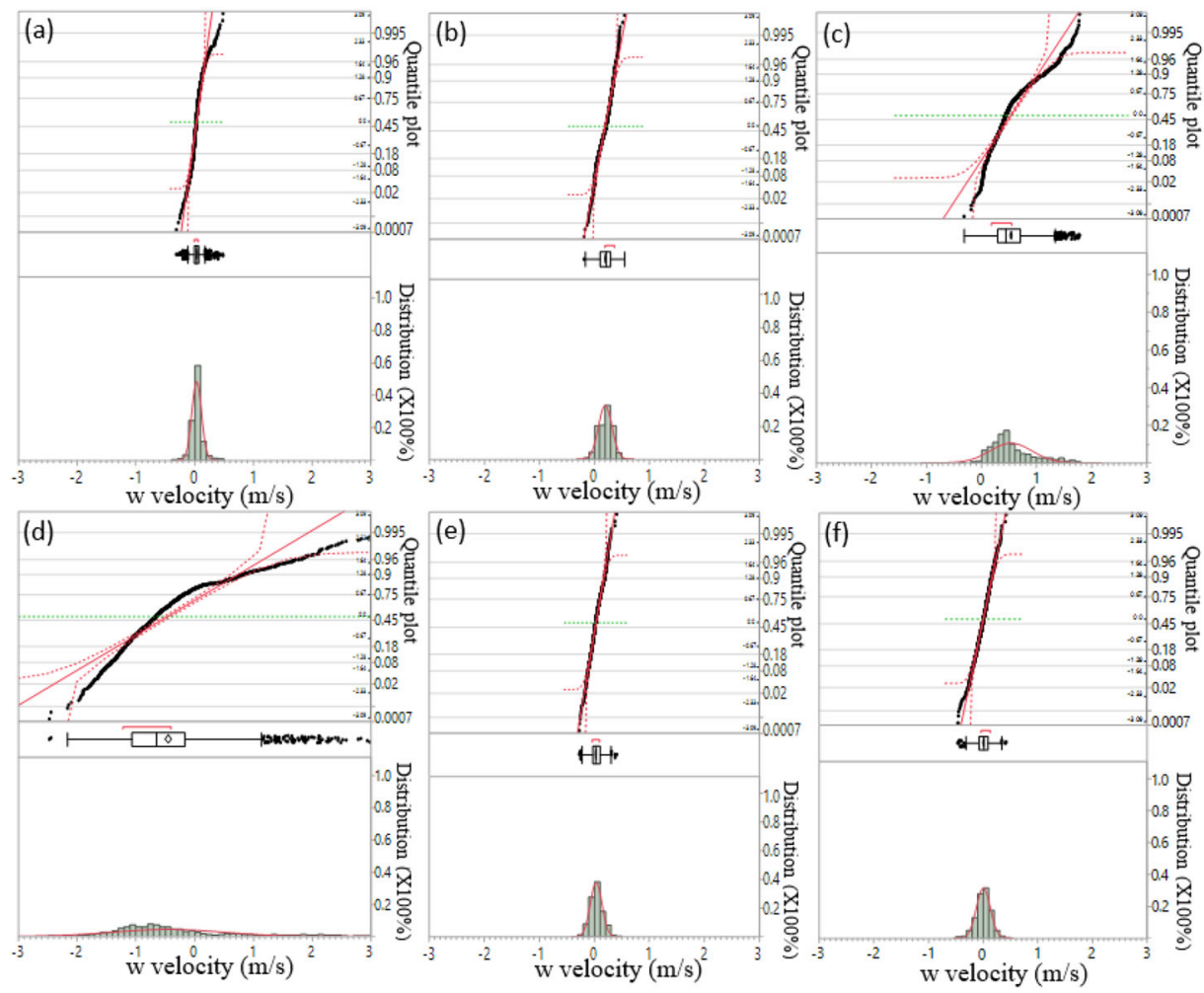

\section{Figure 7. Normal quantile plot, box-and-whisker plots, and distributions of $w$ velocity at different cross sections of the funnel at $t=900 \mathrm{~s}$ in scenario 1 at: (a) $430 \mathrm{~m}$ upstream, (b) $10 \mathrm{~m}$ upstream, (c) $7 \mathrm{~m}$ upstream, (d) $10 \mathrm{~m}$ downstream, (e) $100 \mathrm{~m}$ downstream, (f) 430 downstream.}

cross section and the burning source which created a chaotic fluid structure in the middle of the computational domain. The sudden contraction of the cross section, due to the presence of the vehicle, and the burning source, resulted in the creation of the vorticities in the region near the fire field. The dispersion of the longitudinal and transversal velocities of all nodes decreased from the centerline of the object up to 100 downstream of the fire and it remained almost constant up to the outlet. The dispersion of the longitudinal velocity $(\mathrm{u})$ of all nodes at different cross sections downstream of the fire was higher compared to the dispersion of the transversal velocities. This study has shown that the transversal velocities ( $\mathrm{v}-$ and w- velocities) were temperature dependent just near the fire field while the temperature did not affect the dispersion of the transversal velocities of all nodes along the height of the tunnel far from the fire. On the contrary, the longitudinal velocity (u-velocity) was temperature dependent at both near and far fire fields. In other words, the streamwise component of the velocity (u-velocity) is more temperature dependent than the transversal velocity components ( $\mathrm{v}$ - and $\mathrm{w}$-velocities). 


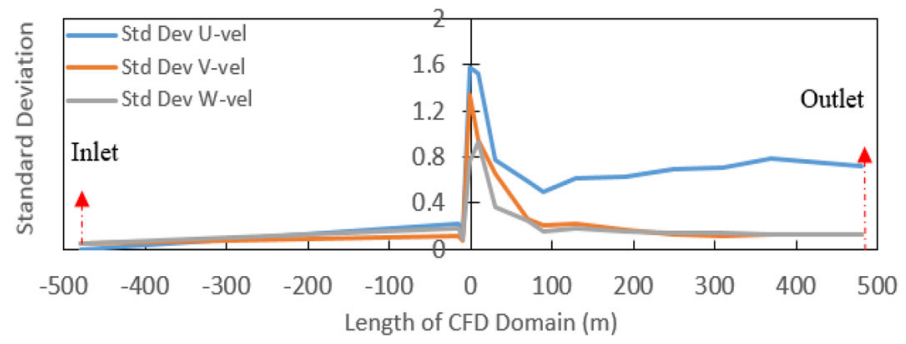

\section{Figure 8. Standard deviation of $u-, v-$, and $w$-velocities at different cross sections of the tunnel in scenario 1.}

The contour plots of the longitudinal velocity ( $u$ velocity) and the transversal velocities (v-velocity and w-velocity) at different cross sections downstream of the fire in scenario 1 at $\mathrm{t}=900 \mathrm{~s}$ are shown in Fig. 9 which highlights the findings above and give a visual representation of the velocity fields.

Overall, because of the complex dynamical fluid field close to the fire $(10 \mathrm{~m}$ upstream of the fire to $100 \mathrm{~m}$ downstream), the wide dispersion of the values (e.g., velocity components) was observed, dispersion decreases in the far field.

The same study was conducted for scenarios 2 and 3 in order to investigate the behavior of the longitudinal and the transversal velocity components of all nodes along the height of tunnel at different cross sections when the velocity and HRR were changed (see Appendix 1 for normal quantile plot, box-and-whisker plots, distributions of $\mathrm{u}-, \mathrm{v}-$, and $\mathrm{w}$-velocities of all nodes, and standard deviations at different cross sections of the tunnel at $t=900 \mathrm{~s}$ for scenarios 2 and 3). Similar dispersion characteristics near and far field of the fire were observed for scenario 2, which increased the HRR to $30 \mathrm{MW}$. Because of downwind transport of smoke and hot gases in scenario 2, the dispersion of the longitudinal and transversal velocities at different cross sections upstream of the fire did not change by changing HRR. Therefore, the only region which the standard deviation of the transversal velocity components was affected by changing the HRR, was distinguished as a $10 \mathrm{~m}$ upstream of the fire to $100 \mathrm{~m}$ downstream as shown in Fig. 23a (See Appendix 1).

It is noteworthy that by changing the HRR the dispersion of the transversal velocities ( $v$ - and w-velocities) at the near fire field were changed while the dispersion of the transversal velocities of all nodes along the height of the tunnel far from the fire was not affected. On the contrary, the longitudinal velocity (u-velocity) was temperature dependent at both near and far fire fields.

A velocity less that the critical velocity $\left(\mathrm{V}<\mathrm{V}_{\mathrm{c}}\right)$ was considered in scenario 3 . Therefore, because of the backlayering phenomenon, the distribution and the dispersion of longitudinal velocity of all nodes along the height of the tunnel at a different cross section upstream of the tunnel were different in comparison with the longitudinal velocity values of all nodes at upstream in scenarios 1 and 2 . Consistent with the data of Fig. 20 (See Appendix 1), it is evident that the longitudinal velocity of all nodes at different cross sections from the inlet to $170 \mathrm{~m}$ upstream of the fire was positive and had a normal distribution. From 170 

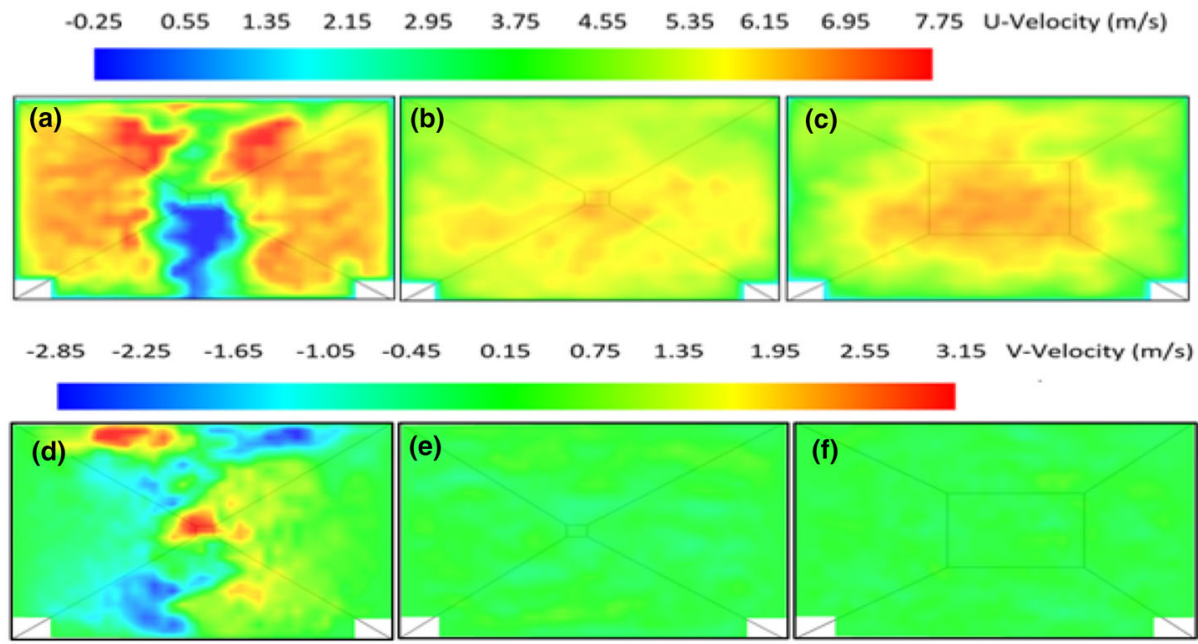

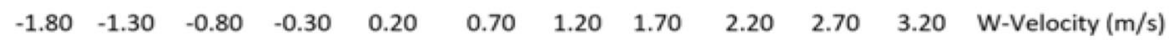

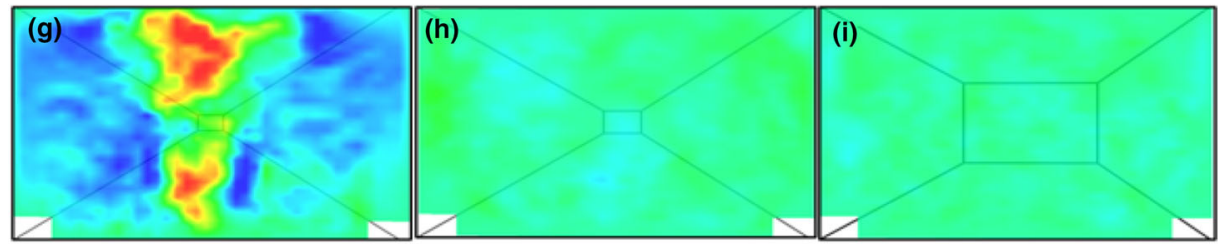

\section{Figure 9. Velocity contour plots at different cross sections of the tunnel at t = $900 \mathrm{s:}$ (a) $10 \mathrm{~m}$ downstream, (b) $100 \mathrm{~m}$ downstream, (c) 430 downstream, (d) $10 \mathrm{~m}$ downstream, (e) $100 \mathrm{~m}$ downstream, (f) 430 downstream, (g) $10 \mathrm{~m}$ downstream, (h) $100 \mathrm{~m}$ downstream, (i) 430 downstream.}

upstream of the fire to the centerline, the negative longitudinal velocity at some nodes of different cross sections was calculated. The reason lies in the buoyancy forces associated with the temperature of the smoke plume, which causes it to overcome the inertial forces of the ventilation air [16]. Therefore, this region was not considered as the upstream interface boundary since the quasi-1D flow-field criterion was not met. In addition, according to Fig. 23b (see Appendix 1), the dispersion of longitudinal velocity of all nodes at different cross sections from the inlet to $180 \mathrm{~m}$ upstream of the fire source remained constant and after that, it increased dramatically. This study has shown that not only the whole back layering region but also $10 \mathrm{~m}$ before that region should not be considered as the upstream interface boundary region. The longitudinal and the transversal velocity components downstream of the fire were distributed normally from $100 \mathrm{~m}$ downstream of the fire up to the outlet. According to Fig. 23b (see Appendix 1), the standard deviation of the longitudinal and the transversal velocities along the height of the tunnel at different cross sections from the inlet to the outlet 

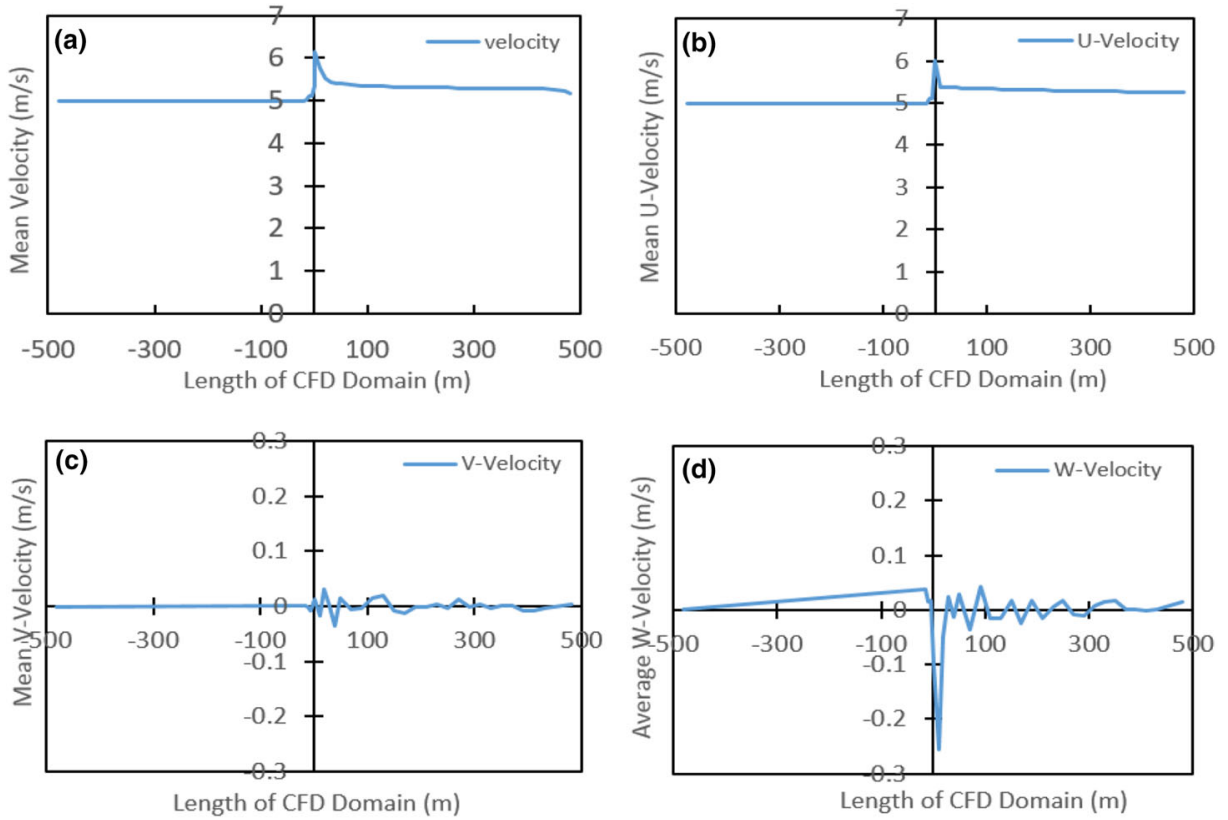

\section{Figure 10. The mean velocity and its components along the height of the tunnel at different cross sections at $t=900 \mathrm{~s}$ in scenario 1 (a) velocity, (b) u-velociły, (c) v-velociły, (d) w-velociły.}

remained constant except for the region $180 \mathrm{~m}$ upstream of the fire to $100 \mathrm{~m}$ downstream of the fire.

\subsubsection{Mean Velocity and Mean Velocity Components The mean velocity and its} components along the height of the tunnel at different cross sections in scenario 1 were investigated in order to distinguish the near and far fields via determination of the significance of the mean components of the velocity on the fluid structure at different cross sections of the tunnel. In addition, due to the continuity of the average velocity at the 3D-1D interface boundaries, the mean velocity (10 (a)) and its components (10 (b), 10 (c), and 10 (d)) along the height of the tunnel at different cross sections were investigated as shown in Fig. 10.

It is noteworthy that the mean velocity and the mean longitudinal velocity (uvelocity) at a different cross section of the tunnel behaved the same except the near fire field. The reason lies in the erratic behavior of the mean transversal velocities (v-velocity and w-velocity) near the fire source as shown in Fig. 10c, d. Consistent with the data of Fig. 10b it was evident that the mean longitudinal velocity (u-velocity) remained constant from the inlet to $10 \mathrm{~m}$ upstream of the fire and after that, it experienced large fluctuations to $20 \mathrm{~m}$ downstream of the fire. Then, it leveled off up to the outlet. The mean longitudinal velocity upstream and downstream of the fire were calculated at $5 \mathrm{~m} / \mathrm{s}$, and $5.3 \mathrm{~m} / \mathrm{s}$, respectively. The magnitude of the mean longitudinal velocity compared to the mean transversal 
velocities is significantly higher at different cross sections of the tunnels as shown in Fig. 10b, c and d. According to Fig. 10c, d, the mean transversal velocities are sporadic from $10 \mathrm{~m}$ upstream to $100 \mathrm{~m}$ downstream of the fire and after that, they display only marginal fluctuations. The mean transversal velocities ( $\mathrm{v}-$ and $\mathrm{w}-$ velocities) at upstream of the fire remained constant from the inlet to $10 \mathrm{~m}$ upstream of the vehicle fire. According to Fig. 10c, the mean v-velocity fluctuated from $-0.05 \mathrm{~m} / \mathrm{s}$ to $0.05 \mathrm{~m} / \mathrm{s}$ in that region while the mean w-velocity (Fig. 10d) fluctuated from $-0.25 \mathrm{~m} / \mathrm{s}$ to $0.04 \mathrm{~m} / \mathrm{s}$ in the same region. The effect of the mean transversal velocities on mean velocity was observed to be consequential at near fire field, $10 \mathrm{~m}$ upstream to $100 \mathrm{~m}$ downstream of the fire. Consequently, this study has shown that the longitudinal velocity (u-velocity) dominated the fluid field far from the fire source. Hence, the fluid field in that region was quasi-1D.

The mean velocity and the mean longitudinal and transversal velocities in scenario 2 behaved similarly to scenario 1 (see Appendix 2 for mean velocity, mean longitudinal velocity (u-velocity), and mean transversal velocities (v-velocity and $\mathrm{w}$-velocity) along the height of the tunnel at different cross sections at $\mathrm{t}=900 \mathrm{~s}$ for scenarios 2 and 3). According to Fig. 24 (see Appendix 2), the effect of the mean transversal velocities ( $\mathrm{v}$ - and $\mathrm{w}$-velocities) on the mean velocity in scenario 2 was consequential in the near fire field $(10 \mathrm{~m}$ upstream to $100 \mathrm{~m}$ downstream of the fire source). However, in other cross sections of the tunnel, the mean longitudinal velocity (u-velocity) dominated the flow field in scenario 2 . Due to the higher HRR (30 MW) in scenario 2, the mean velocity values were higher downstream of the fire in comparison with the same values in scenario 1. Due to the backlayering phenomenon in scenario 3, the flow did not behave as a 1D fluid in the region from 170 upstream of the fire to the centerline as shown in Fig. 25 (See Appendix 2). The mean velocity and the mean velocity components at different cross sections downstream of the fire in scenario 3 behave similarly to the same region in scenarios 1 and 2 . Therefore, the flow field was dominated by the longitudinal velocity (u-velocity) at different cross sections downstream of the fire except for the region from the centerline of the fire to $100 \mathrm{~m}$ downstream. Moreover, the velocity of airflow remained constant from the inlet to $180 \mathrm{~m}$ upstream of the fire and then it increased up to $90 \mathrm{~m}$ upstream of the fire as shown in Fig. 25a (see Appendix 2). From $90 \mathrm{~m}$ upstream of the fire to $2 \mathrm{~m}$ upstream of the fire source, the airflow velocity changes were inconsequential. The velocity increased dramatically from $2 \mathrm{~m}$ upstream of the fire to $3 \mathrm{~m}$ downstream and then it decreased drastically up to $50 \mathrm{~m}$ downstream of the fire and it leveled off up to the outlet. This study has shown that from $170 \mathrm{~m}$ upstream of the fire to $100 \mathrm{~m}$ downstream of the fire, the transversal velocity component effects were consequential. In this region, the longitudinal velocity is not the dominant component of the fluid field. Therefore, the interface boundaries should be located beyond this region.

This study has shown that the effect of the temperature on the mean transversal velocities along the height of the tunnel at different cross sections close to fire is more consequential compared to the region far from the fire. Due to this, the mean transversal velocities played a key role on the changes of the mean velocity in the near fire field. However, the effect of the mean transversal velocities on the 
changes of the mean velocity at the far fields was not significant. Therefore, the mean longitudinal velocity was the dominant component of the airflow velocity on the fluid structure.

\subsubsection{Ratio Between Maximum Longitudinal and Maximum Transversal Veloci-} ties For adoption of the multiscale methodology, the CFD (3D) and 1D models should be applied to the near field and far field, respectively. Hence, there is a need to determine the quasi-1D region in the computational domain. According to the previous studies, it was evident that the flow structure was quasi-1D when the maximum longitudinal velocity ratio was almost twice the maximum transversal velocities [45]. Therefore, a study was conducted to investigate the maximum longitudinal velocity ratio to the maximum transversal velocities along the height of the tunnel at different cross sections in the steady state condition as shown in Fig. 11.

Due to the transport of smoke and hot gases downstream of the fire source in the scenarios 1 and 2, the ratio of maximum longitudinal velocity to maximum transversal velocities different cross sections just downstream of the fire was investigated. However, because of the back layering phenomenon in the scenario 3, the investigation of maximum longitudinal velocity ratio to the maximum transversal velocities was carried out on the whole domain. Figure 11 shows that the ratio increased dramatically within the first $100 \mathrm{~m}$ downstream of the fire in all scenarios and after that, the values remained within the range of 10 to 20. Consistent with the data of the maximum longitudinal velocity ratio to the maximum transversal velocities downstream of the fire, it was evident that beyond $100 \mathrm{~m}$ downstream of the fire the flow is almost one-dimensional because of the domination of the longitudinal velocity in the fluid field. In addition, this study has shown that by the change in HRR, the domination of longitudinal velocity on the fluid flow did not change significantly.

The maximum longitudinal velocity ratio to the maximum transversal velocity was calculated within the range of 28 to 40 from the inlet to $300 \mathrm{~m}$ upstream of the fire in scenario 3 . Then the ratio decreased noticeably to 8 , at $250 \mathrm{~m}$ upstream of the fire. The ratio experienced marginal fluctuation from $250 \mathrm{~m}$ to $90 \mathrm{~m}$ upstream of the fire. The maximum longitudinal velocity ratio to the maximum transversal velocities experienced sporadic behavior from $90 \mathrm{~m}$ upstream of the fire to the centerline. The reason lies in that the smoke layer depth, and higher temperature close to the fire source. This study has highlights the previous findings that close to fire source the domination of the transversal velocities on the fluid structure increased. Moreover, the ratio was within a range of 10 to 20 in the quasi-1D region downstream of the fire source. Therefore, a ratio of at least 10 was recommended to indicate that longitudinal velocity component is dominant.

\subsection{Turbulent Kinetic Energy and Vorticity Analysis}

The energy content of eddies in turbulent flows is characterized by Turbulent Kinetic Energy (TKE); larger TKE values indicate higher energy content of eddies. The existence of eddies indicates the rotation of the fluid particles or vor- 

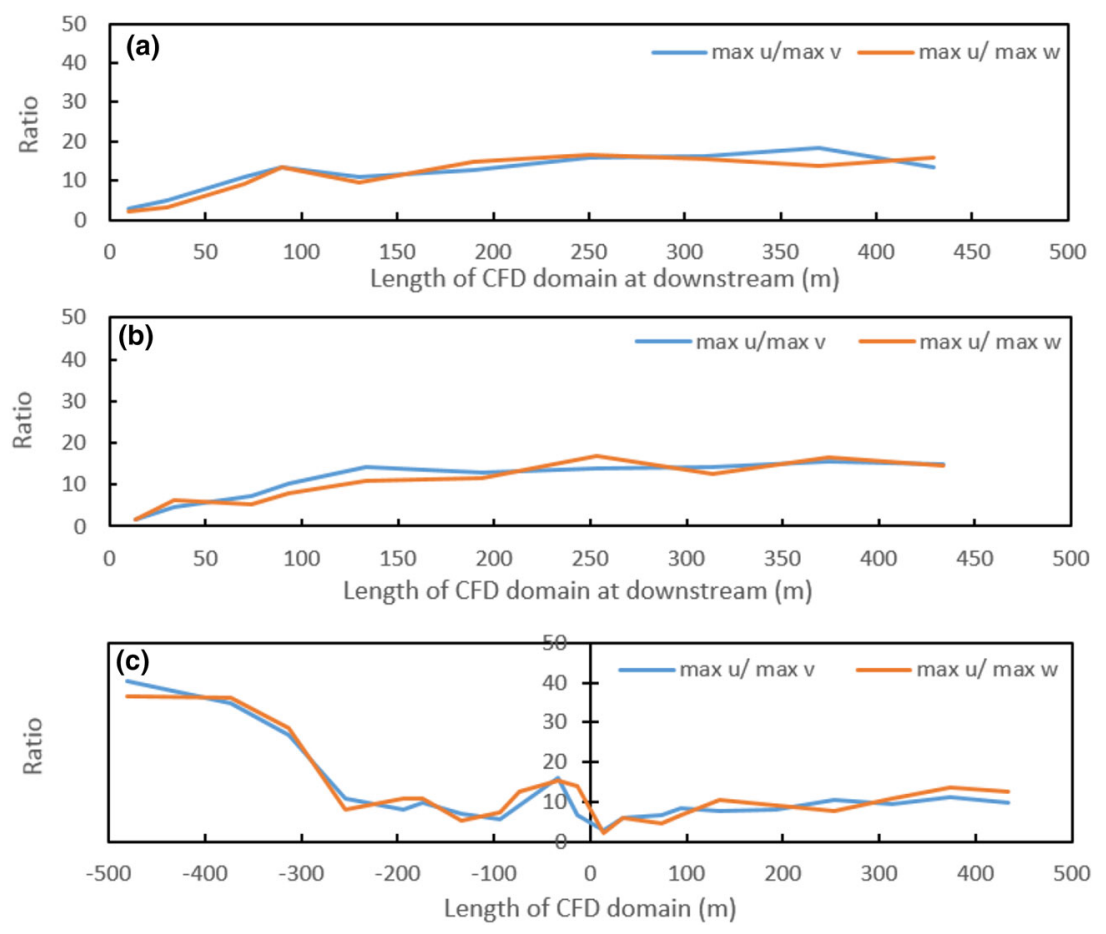

\section{Figure 11. The maximum longifudinal velocity ratio to the maximum transversal velocities along the height of the tunnel at different cross sections at t = 900 s: (a) scenario 1 , (b) scenario 2 , (c) scenario 3.}

ticity. Therefore, diffusion will be intensified with the existence of eddies. Since the turbulent flows are dissipative, the kinetic energy of larger eddies will be transferred to the smaller ones, and finally, the kinetic energy of the smallest eddies will be converted into heat due to the viscous shear stresses. In some cases, backscatter phenomenon can occur which it means that because of the interaction of the smaller eddies with each other, the kinetic energy will be transferred to the larger eddies [7, 23, 44]. In order to determine the region where the transversal velocity components have an inconsequential effect on the fluid field, the tendency of fluid particles to rotate (vorticity) along the different axes (X, Y, and Z), was investigated. In addition, for characterizing the intensity of turbulence of a system, the Turbulent Kinetic Energy (TKE) analysis along the height of the tunnel at different cross sections was conducted. Then the one-dimensional flow pattern region was determined by the usage of mean TKE and mean vorticity analysis. The mean TKE of the cross sections and the mean vorticity along $\mathrm{X}, \mathrm{Y}$, and $\mathrm{Z}$ axis at different cross sections along the height of the tunnel at $t=900$ for all scenarios were calculated as shown in Fig. 12.

According to Fig. 12a, the mean TKE at different cross sections in scenario 1 remained constant from the inlet to $10 \mathrm{~m}$ upstream of the fire. After that point, the mean TKE fluctuated substantially to $50 \mathrm{~m}$ downstream; then, it leveled off up 

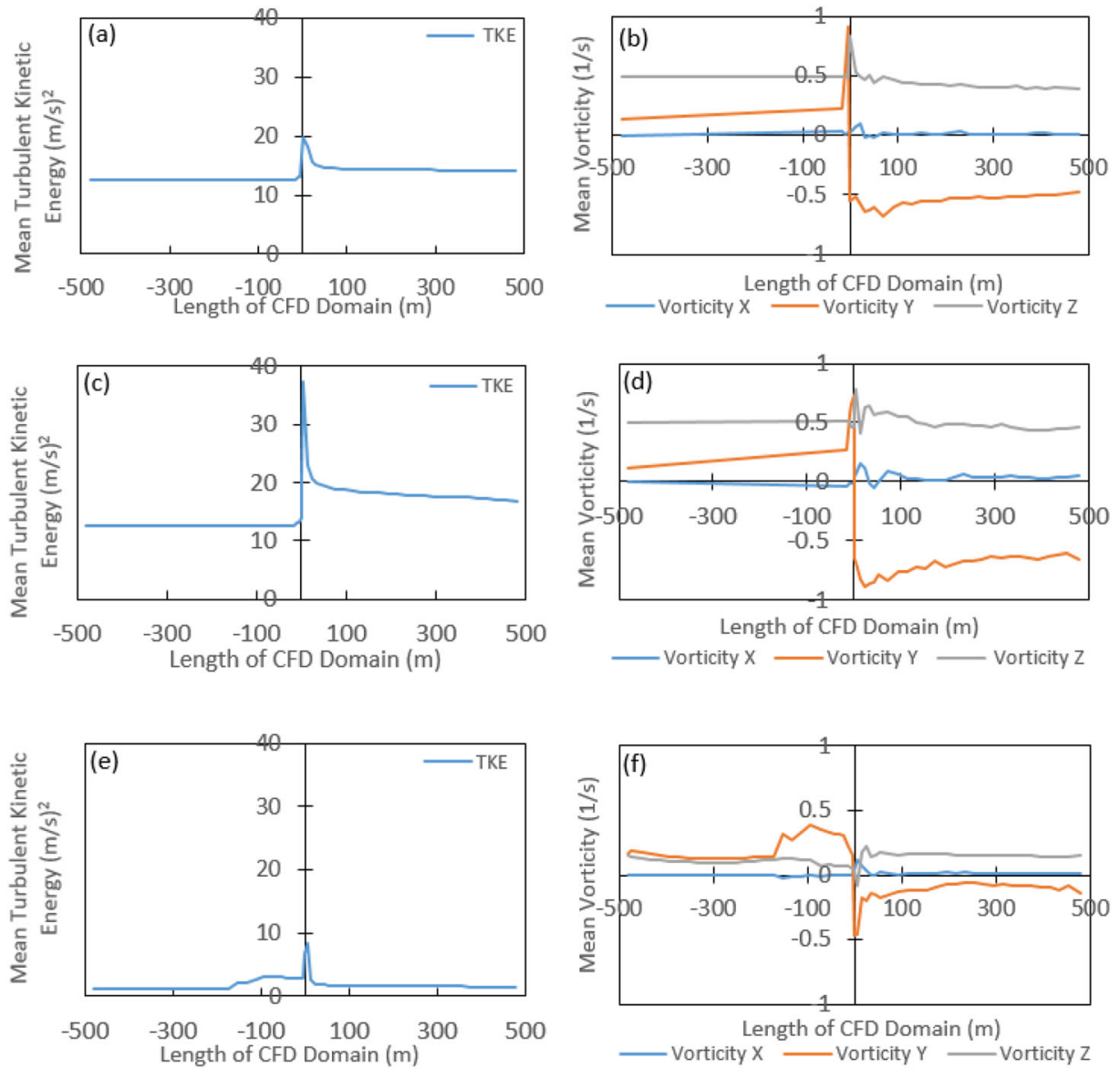

Figure 12. The mean TKE and the mean vorticity along the height of the tunnel at different cross sections at $t=900$ in all scenarios: (a) mean TKE scenario 1 , (b) mean vorticiły scenario 1 , (c) mean TKE scenario 2, (d) mean vorticity scenario 2, (e) mean TKE scenario 3, (f) mean vorticity scenario 3.

to the outlet. Consistent with the data of the vorticity along $\mathrm{X}, \mathrm{Y}$, and $\mathrm{Z}$ axis in scenario 1 (Fig. 12b), it was evident that the mean vorticity along $X, Y$, and $Z$ axes experienced wild fluctuations in a region $10 \mathrm{~m}$ upstream of the fire to $100 \mathrm{~m}$ downstream. The changes of the mean vorticity along $\mathrm{X}, \mathrm{Y}$, and $\mathrm{Z}$ axes at different cross sections of the tunnel in scenario 1 were inconsequential as plotted in Fig. 12b. When HRR was altered, the trend of the mean TKE and the mean vorticity along $\mathrm{X}, \mathrm{Y}$, and $\mathrm{Z}$ axis at different cross sections did not change; however, the values changed as shown in Fig. 12c, d. Therefore, the mean TKE and the mean vorticity along a different axis in scenario 2 experienced erratic behavior from $10 \mathrm{~m}$ upstream of the fire to $100 \mathrm{~m}$ downstream. This study has shown that 
the fluid particles had the highest tendency to rotate along $\mathrm{X}, \mathrm{Y}$, and $\mathrm{Z}$ axis at the near fire field.

The behavior of the mean TKE and the mean vorticity along $\mathrm{X}, \mathrm{Y}$, and $\mathrm{Z}$ axis downstream of the fire in scenario 3 was observed to have the same as the behavior of associated values in scenarios 1 and 2 as shown in Fig. 12e, f. Due to lower velocity in scenario 3 compare to scenario 1 and 2, the mean TKE and the mean vorticity downstream of the fire were calculated lower than the values in scenario 1 and 2. The values remained constant from the inlet to $170 \mathrm{~m}$ upstream of the fire. Because of the backlayering phenomenon in scenario 3, the mean TKE and the mean vorticity along the $\mathrm{Y}$ and $\mathrm{Z}$ axes experienced substantial fluctuations from $170 \mathrm{~m}$ upstream of the fire to the centerline. The vorticity along the $\mathrm{X}$ axis was almost zero at all cross sections except the regions close to the fire source. Consequently, it was evident that the intensity of turbulent kinetic energy and the rotation tendency of fluid particles remained constant in the regions where the flow field is quasi-1D.

According to the longitudinal and the transversal velocity components analysis and the TKE and the vorticity analysis, the quasi-1D regions were determined in order to couple $3 \mathrm{D}$ to $1 \mathrm{D}$ models. The upstream and downstream interface boundaries were determined for all scenarios as shown in Fig. 13.

Based on the physics of the fluid structure, TKE, and the vortex dynamics, interface boundaries were placed $10 \mathrm{~m}$ upstream of the fire source and $100 \mathrm{~m}$ downstream for scenarios 1 and 2. Because of the consequential effect of the transversal velocity components ( $\mathrm{v}$ and $\mathrm{w}$ velocities) on the flow field characteristic near the fire field at upstream, the upstream interface boundary could not be moved closer than $10 \mathrm{~m}$ to the fire object (the calculated distance was from the centerline). The distance from upstream interface boundary to the tip of the object was $0.5 \mathrm{D}_{\mathrm{h}}(4 \mathrm{~m})$. The downstream boundary was calculated to be at least 12 times the hydraulic diameter $\left(\mathrm{D}_{\mathrm{h}}\right)$ which indicated agreement with previous work $[12,45]$. The same downstream interface boundary was selected for scenario 3 as scenarios 1 and 2. Due to significant effect of the transversal velocities (v- and wvelocities) on the fluid flow field close to the tip of the backlayering, the upstream interface boundary was selected $10 \mathrm{~m}$ further from the tip of the backlayering at $180 \mathrm{~m}$ upstream of the fire in scenario 3 as shown in Fig. 13c. It was observed that the fluid flow field at that section was quasi-1D. Therefore, the near fire field (the region between upstream and downstream interface boundary) was determined as shown in Fig. 13 for all scenarios.

\section{Coupled Simulation Results}

The 1D models were simulated using VentFIRE in order to couple to the full CFD simulations. The airways and the airflow charactristics were embedded in Ventsim Visual ${ }^{\text {TM }} 4.8$ based on the dimensions and the airflow parameters as discussed. The fixed airflow was set at the tunnnel's inlet and the outlet of the tunnel was set open. The thermal charactristics of the concrete was utilized in the heat simulation and the dynamic increment and maximum subcells were set to $0.1 \mathrm{~s}$ 

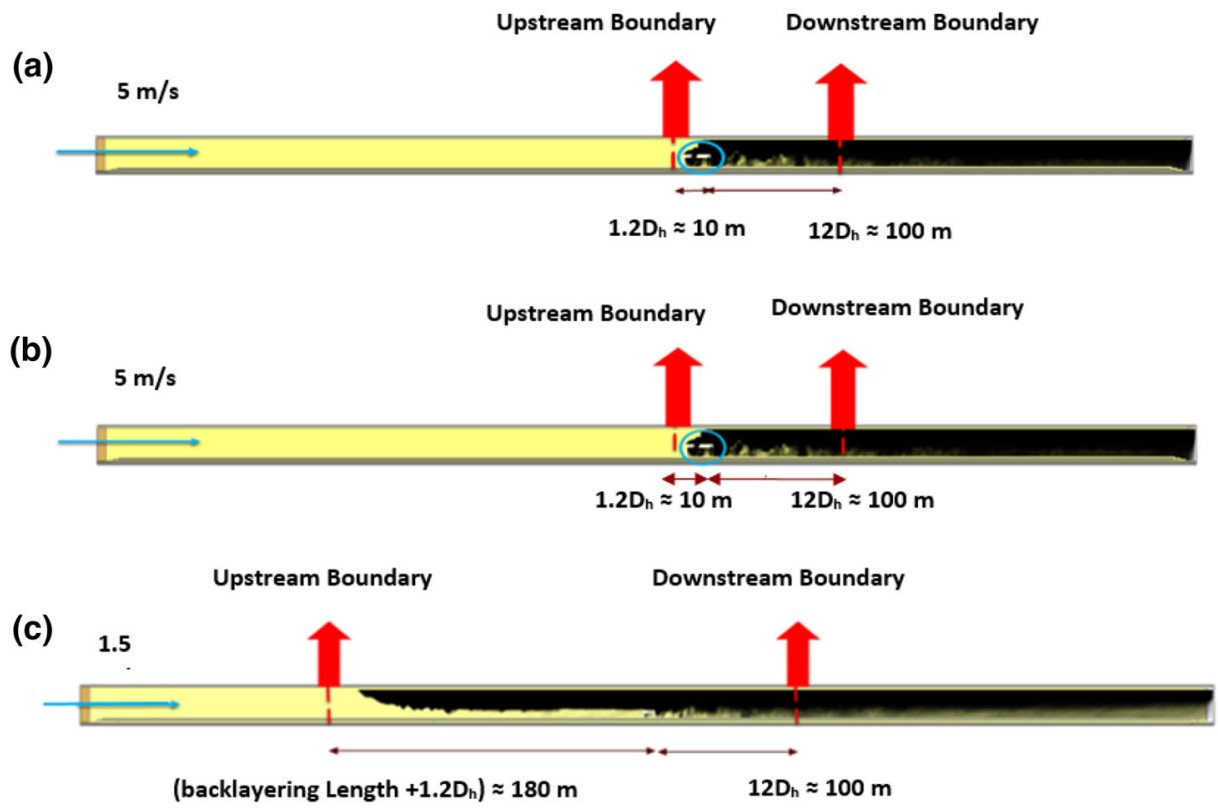

\section{Figure 13. Selected inferface boundaries at upstream and downstream of the fire source (a) scenario 1 , (b) scenario 2, (c) scenario 3 (not to scale).}

\section{Table 3 \\ The Mean Temperature at the Inferface Boundaries for Different Scenarios}

\begin{tabular}{lcc}
\hline Scenarios & Upstream interface temperature $\left({ }^{\circ} \mathrm{C}\right)$ & Downstream interface temperature $\left({ }^{\circ} \mathrm{C}\right)$ \\
\hline Scenario 1 & 20 & 34.3 \\
Scenario 2 & 20 & 71.7 \\
Scenario 3 & 20 & 43.8 \\
\hline
\end{tabular}

and 100 respectively in the dynamic simulation. In addition, every 5 dynamic steps, the airflow was simulated (frequency airflow simulation $=5$ ). It was ensured that the steady state air and heat simulations are balanced and simulated properly before fire simulation. Then the fire events were simulated in the ventFIRE. Flexible polyurethane foam chractristics as shown in Table 1 were utilized for vehicle fire simulation in the tunnels. The same three aforementined scenarios (Table 2) were simulated based on various HRR and the inlet velocities. The tsquared approach was used for the growth of the vehicle fires with a $1 \mathrm{~min}$ as the time to reach maximum HRR ( $\left.\mathrm{t}_{\max }\right)$. All parameters were calculated every $5 \mathrm{~m}$ upwind and downwind from the fire source with the zero as the cross section of the tunnel at the center of the fire source. The multiscale calculations were con- 

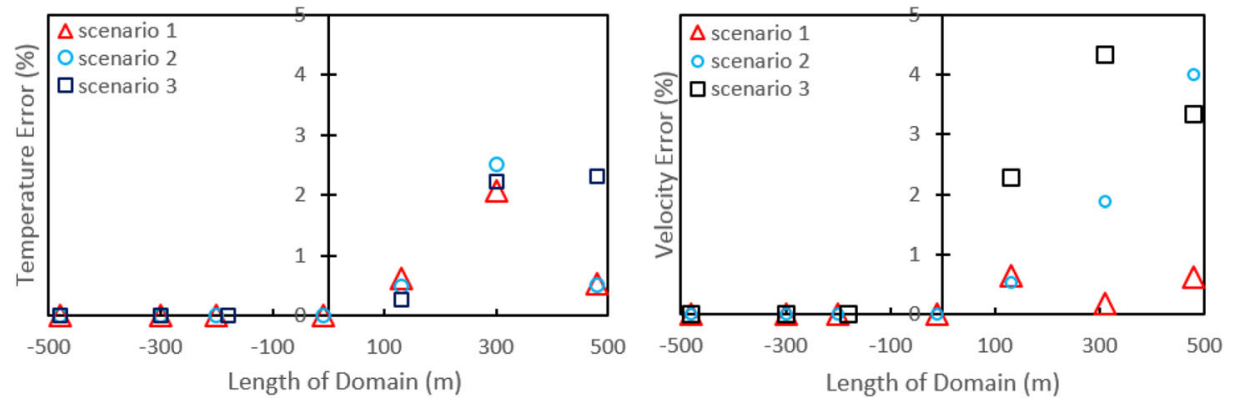

\section{Figure 14. The calculated error between CFD and coupled models for mean temperature and velocity at different cross sections before and after determined interface boundaries for all scenarios: (a) temperafure error, and (b) velocity error.}

ducted using indirect coupling strategy with the near fire field characteristic curves implemented in the 1D models. The characteristic curves of near fire field (CFD region) are required in the indirect coupling of 3D models to $1 \mathrm{D}$ models $[11,12]$. Therefore, the near fire field characteristic points for all scenarios were plotted in terms of mass flow rate versus total pressure drop across the domain boundaries as shown in Appendix 3. Since the continuity of the mean temperature should be met at the interface boundary, the mean temperature along the height of the tunnel at the selected interface boundaries were calculated as shown in Table 3 .

The coupled model was simulated and the associated average temperature and velocity errors in the coupled scenarios compare to the full domain CFD simulations were calculated as shown in Fig. 14 (see Fig. 15 for comparison of coupled model results to 1D models' results for scenarios 1, 2, and 3). According to Fig. 14, the mean temperature and the mean velocity errors at different cross sections after downstream interface boundary were calculated at less than $5 \%$. The error before upstream interface boundary was calculated as a $0 \%$.

Figure 15, shows that the mean temperature errors between 1D and the coupled model at the outlet were $49.2 \%, 66.5 \%$, and $86 \%$ in scenarios 1,2 , and 3 , respectively. Due to the inability of VentFIRE to precisely simulate backlayering phenomenon, a higher percentage of error of the mean temperature in scenario 3 was observed. If we assume that the 3D simulation (CFD) over the whole domain is most representative of reality, then the coupling approach results in a drastic improvement in agreement for the mean temperature results at the far fire field when compared with a 1D simulation over the whole domain. In addition, the mean velocity along the height of the tunnel at the inlet and outlet was improved. The approximate total computational time (CPU time) required for runnning the CFD model, 1D model, and the coupled model for scenario 1 was at $72.8 \mathrm{~h}, 28 \mathrm{~s}$, and $32 \mathrm{~s}$ respectively. The CPU time for CFD simulations in scenarios 2 and 3 increased due to higher HRR and the backlayering phenomenon in scenarios 2 and 3 respectively. It was observed that the coupling strategy is able to increase 
(a)
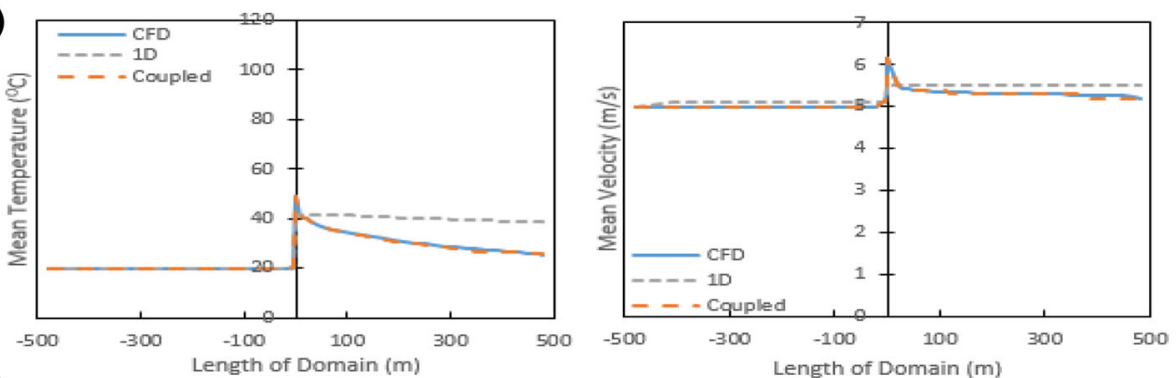

(b)
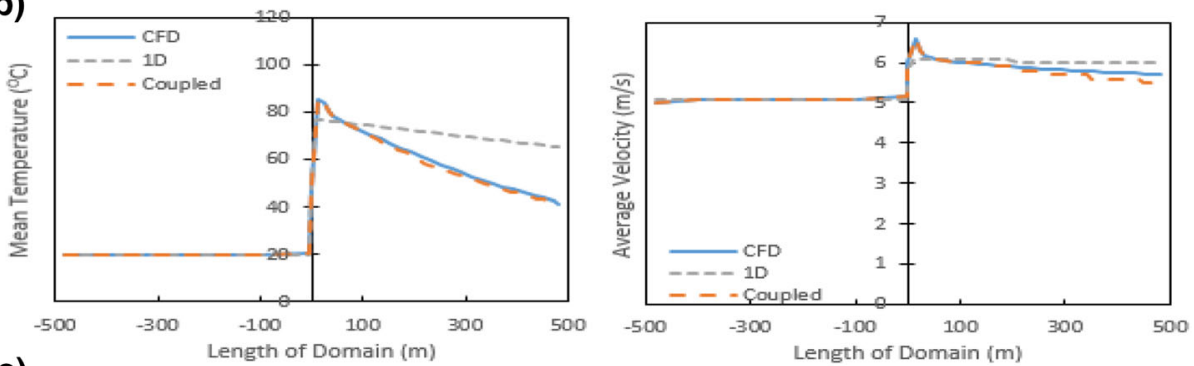

(c)
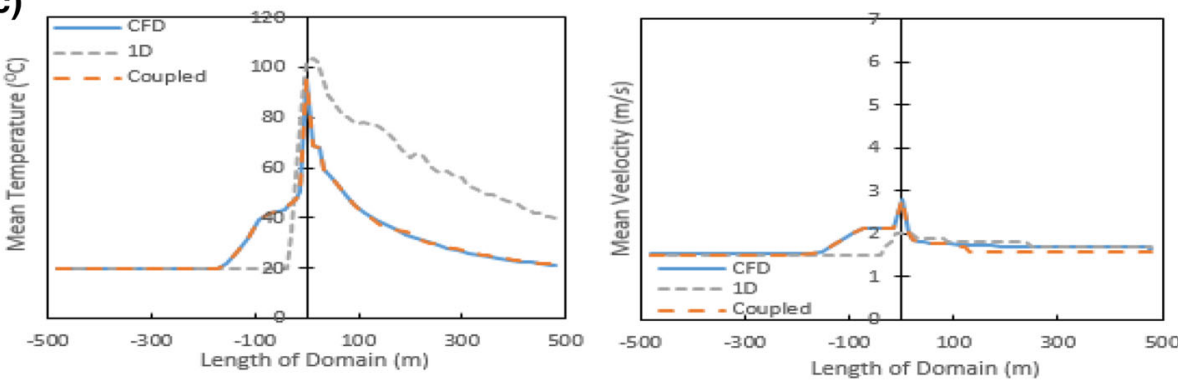

Figure 15. Mean temperature and mean velocity comparison between CFD, ID, and the coupled models at different cross sections of the tunnel for all scenarios (a) scenario 1 , (b) scenario 2 , (c) scenario 3.

the computational efficiency conspicuously while retaining the physics and producing results within $5 \%$ of the full order CFD model.

\section{Modified Procedure for Selection of Interface Boundary in Multiscale Methodology}

Based on the velocity components analysis and the TKE and the vorticity analysis, it is recommended the interface boundary selection procedure for indirect coupling of 3D and 1D models as shown in Fig. 16. First CFD model is the reference model and the most expensive part of the process. Based on the results, we recommend a computational domain of $5 \mathrm{D}_{\mathrm{h}}$ upstream and $20 \mathrm{D}_{\mathrm{h}}$ downstream of the fire 


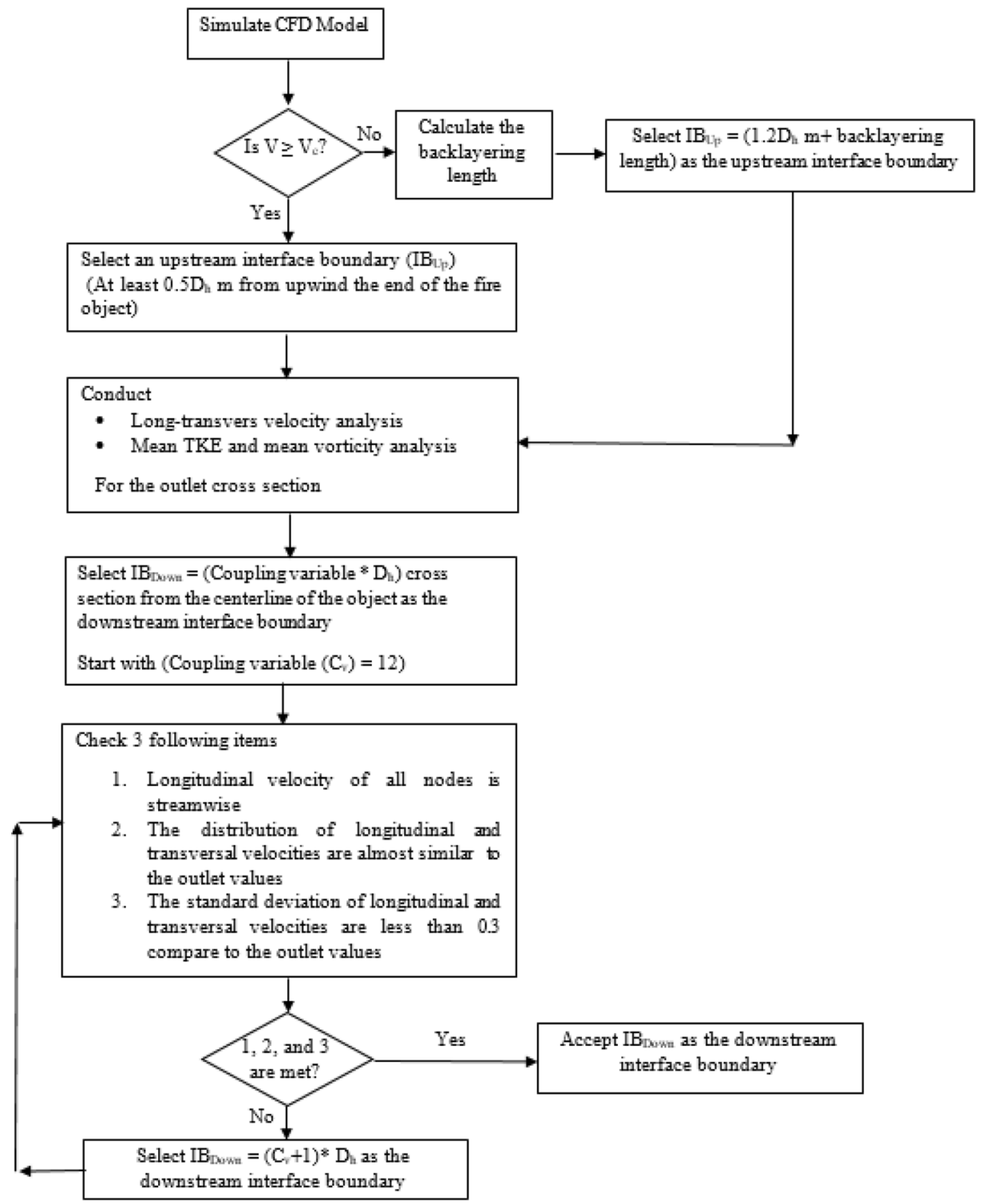

\section{Figure 16. Decision making algorithm for determination of inferface boundary to couple 3D and ID fire simulations in tunnels.}

source as the reference CFD model if the inlet velocity was greater than equal to critical velocity $\mathrm{V} \geq \mathrm{V}_{\mathrm{c}}$ (e.g., there is no backlayering). However, if the inlet velocity was less than critical velocity $\mathrm{V}<\mathrm{V}_{\mathrm{c}}$, the backlayering length should be calculated and be added to the upstream computational domain. Next, the CFD model 
is simulated and the inlet velocity of the domain is determined. If the the determined inlet velocity is greater that or equal to $V_{c}$, the upstream interface boundary is selected at least $0.5 \mathrm{D}_{\mathrm{h}}$ from upwind the end of the fire object. If the selected inlet velocity is less than $\mathrm{V}_{\mathrm{c}}$, the backlayering length should be calculated and (1.2 $\mathrm{D}_{\mathrm{h}} \mathrm{m}+$ backlayering length) should be selected as the upstream interface boundary. For the determination of the downstream interface boundary in both $\mathrm{V} \geq \mathrm{V}_{\mathrm{c}}$ and $\mathrm{V}<\mathrm{V}_{\mathrm{c}}$ scenarios, the longitudinal and the transversal velocities analysis and the mean TKE and mean vorticity analysis for the outlet cross section should be conducted. Next, the $12 \mathrm{D}_{\mathrm{h}}$ cross section from the centerline of the object is selected as the downstream interface boundary which number 12 is the coupling variable $\left(\mathrm{C}_{\mathrm{v}}\right)$. If the longitudinal velocity of all nodes is streamwise, and the distribution of the longitudinal and transversal velocities are almost similar to the outlet values, and the standard deviation of the longitudinal and transversal velocities of the determined section are less than 0.3 compared to the outlet values, that cross section can be accepted as the downstream interface boundary. If one of the explained requirements was not met, then $\left(\mathrm{C}_{\mathrm{v}}+1\right)^{*} \mathrm{D}_{\mathrm{h}}$ is selected as the downstream interface boundary to repeat the longitudinal and the transversal velocities analysis and the mean TKE and mean vorticity analysis for that selected downstream interface boundary. The method will be iterated till all requirements are met. Ultimately, that cross section is accepted as the downstream interface boundary.

It is crucial to consider that the tunnel used in this study was a straight tunnel with just a burning object in the computational domain. Previous studies $[18,31$, 42] have shown that the vehicular blockage influences the flow behavior of tunnel fires, critical velocity $\left(\mathrm{V}_{\mathrm{c}}\right)$, and the backlayering length. If other objects or fire sources (e.g., vehicles) were considered in the simulation domain, the same study should be conducted for determination of the interface boundaries before and after the extra objects are included in the tunnel, because of the effects of the temperature and the vehicular blockage on the fluid structure in the computational domain. The other influential parameter on the interface boundaries is the presence of the jet-fans in the computational domain [11] which the same study should be conducted for determination of the quasi-1D region before and after the considered jet-fans in the domain.

By utilizing this approach, the interface boundaries can be easily selected and adequately applied to couple $3 \mathrm{D}$ and $1 \mathrm{D}$ simulations as shown in Fig. 16. In Fig. 16, $\mathrm{IB}_{\mathrm{Up}}, \mathrm{IB}_{\text {Down }}$, and $\mathrm{C}_{\mathrm{v}}$ are upstream interface boundary, downstream interface boundary, and coupling variable respectively.

\section{Conclusion}

The fundamental longitudinal and the transversal velocities analysis and the TKE and the vorticity analysis for the steady state condition of the full CFD models were utilized to determine interface boundaries for coupling of $1 \mathrm{D}$ and $3 \mathrm{D}$ simulations. The selected downstream interface boundary was $12 \mathrm{D}_{\mathrm{h}} \mathrm{m}$ downstream of the fire for the simulations. The upstream interface boundary selection depends on 
the utilized velocity in the model. The upstream interface boundary was selected at $\left(0.5 \mathrm{D}_{\mathrm{h}}\right) 4 \mathrm{~m}$ upstream the tip of the object when the velocity was greater than equal to the $\mathrm{V}_{\mathrm{c}}$. In the simulations with backlayering $\left(\mathrm{V}<\mathrm{V}_{\mathrm{c}}\right)$, the interface boundary was selected $10 \mathrm{~m}$ further from the tip of the backlayering $\left(1.2 \mathrm{D}_{\mathrm{h}}\right)$. The novel methodology was applied to a tunnel with $73.73 \mathrm{~m}^{2}$ cross section and $960 \mathrm{~m}$ in length. The indirect coupling strategy was utilized to couple $3 \mathrm{D}$ sub-domain to 1D sub-domains. The calculated temperature and velocity errors between multiscale models and the full CFD models were less than $5 \%$. It was evident that the longitudinal velocity component was affected by the temperature more than the transversal velocity components in the whole computational domain. In other words, the longitudinal velocity (u-velocity) was temperature dependent in the whole computational domain while the transversal velocity components ( $\mathrm{v}$ and $\mathrm{w}$ velocities) were temperature dependent just at the near field. It was observed that the temperature did not impact the transversal velocities at the far field. Due to this, the fluid field was observed the quai-1D fluid which the longitudinal velocity dominated the fluid structure.

Consequently, a novel iterative methodology was developed according to the physics of the fluid structure, TKE, and the vortex dynamics for selection of interface boundary to couple 3D and $1 \mathrm{D}$ models for all kinds of fire in the road tunnel or more complex underground space environments. Additionally, the work agrees well with previous work that uses a more exhaustive systematic method (gradually increasing the CFD domain and decreasing the 1D domain until a predetermined error level is encountered.) The proposed methodology was demonstrated to be a useful technique for the determination of near and far fire fields, and could be applied across a broad range of flow simulations.

\section{Acknowledgements}

This research was developed under Contract No. 200-2014-59669, awarded by the National Institute for Occupational Safety and Health (NIOSH). The findings and conclusions in this report are those of the authors and do not reflect the official policies of the Department of Health and Human Services; nor does mention of trade names, commercial practices, or organizations imply endorsement by the U.S. Government.

\section{Open Access}

This article is distributed under the terms of the Creative Commons Attribution 4.0 International License (http://creativecommons.org/licenses/by/4.0/), which permits unrestricted use, distribution, and reproduction in any medium, provided you give appropriate credit to the original author(s) and the source, provide a link to the Creative Commons license, and indicate if changes were made. 


\section{Appendix}

\section{Appendix 1: Longitudinal and Transversal Velocity Components Analysis for Scenarios 2 and 3}

The results of the longitudinal and the transversal velocity components analysis for scenarios 2 and 3 at different cross sections at $\mathrm{t}=900 \mathrm{~s}$ are presented in Figs. 17, 18, 19, 20, 21 and 22. The normal quantile plot, box-and-whisker plots, distributions of $\mathrm{u}, \mathrm{v}$, and $\mathrm{w}$ velocities of all nodes, and standard deviations at different cross sections of the tunnel were plotted during the steady state condition. In addition, the dispersion of the longitudinal and transversal velocities in scenarios 2 and 3 are demonstrated in Fig. 23. This study has shown that the longitudinal and transversal velocities distribution in scenario 2 behaved as same as the
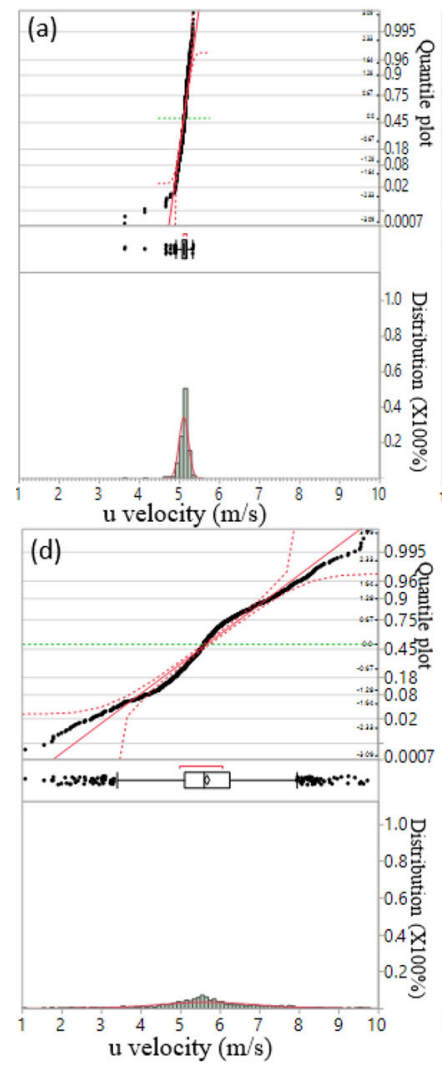
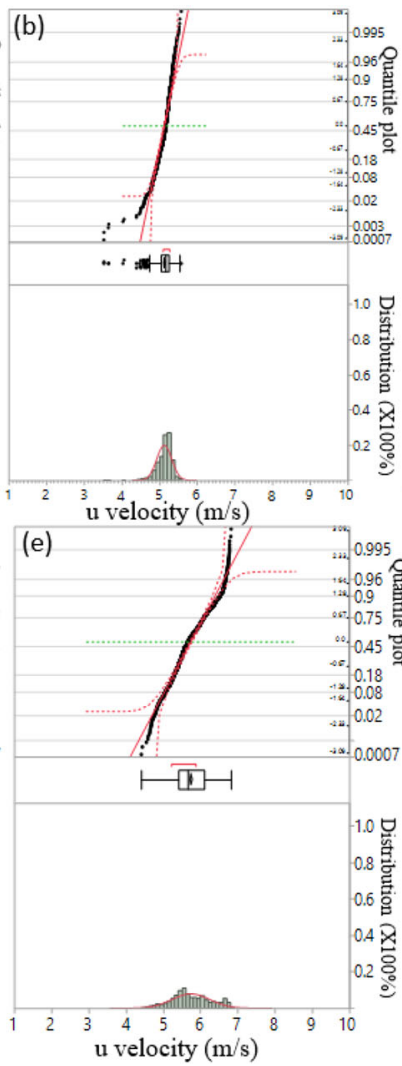
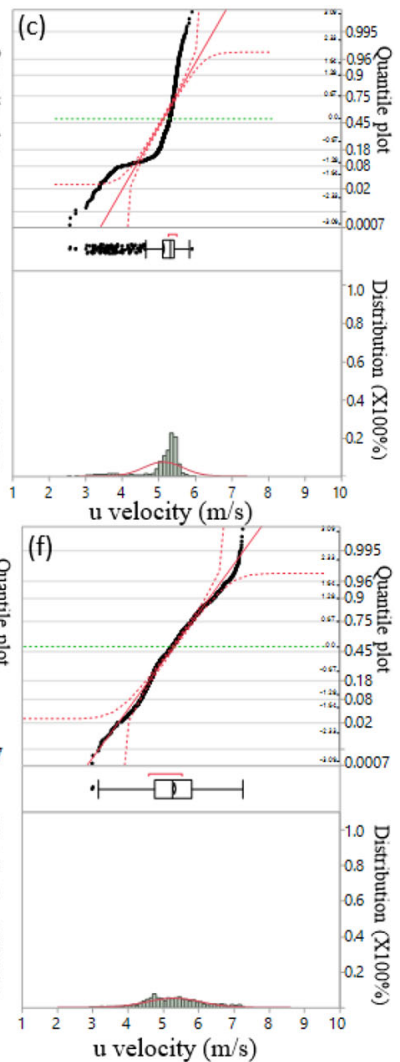

Figure 17. Normal quantile plot, box-and-whisker plots, and distributions of $u$ velocity at different cross sections of the tunnel at $t=900 \mathrm{~s}$ in scenario 2 at: (a) $430 \mathrm{~m}$ upstream, (b) $10 \mathrm{~m}$ upstream, (c) $7 \mathrm{~m}$ upstream, (d) $10 \mathrm{~m}$ downstream, (e) $100 \mathrm{~m}$ downstream, f 430 downstream. 

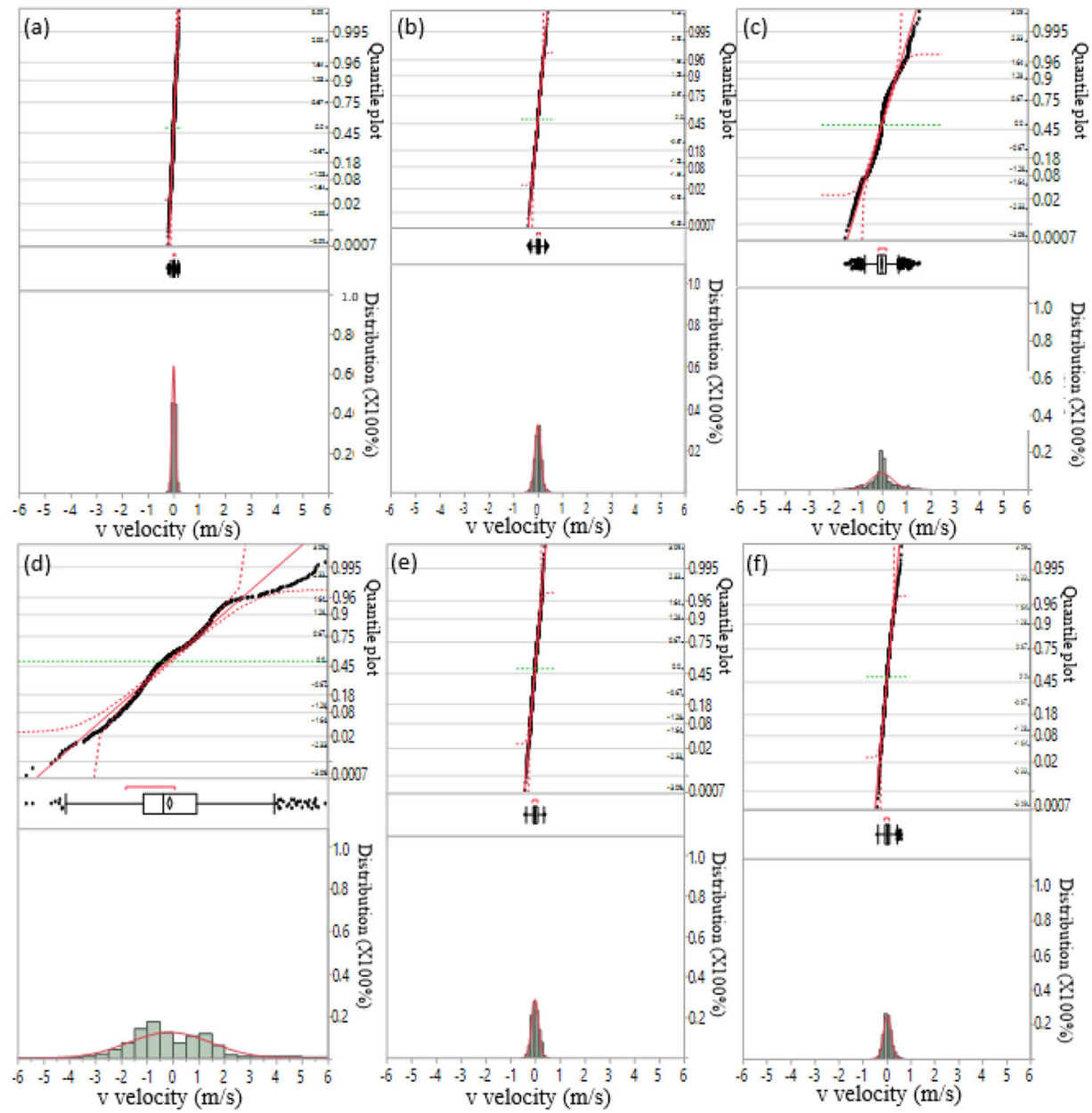

Figure 18. Normal quantile plot, box-and-whisker plots, and distributions of $\mathbf{v}$ velocily at different cross sections of the tunnel at $t=900 \mathrm{~s}$ in scenario 2 at: (a) $430 \mathrm{~m}$ upstream, (b) $10 \mathrm{~m}$ upstream, (c) $7 \mathrm{~m}$ upstream, (d) $10 \mathrm{~m}$ downstream, (e) $100 \mathrm{~m}$ downstream, (f) 430 downstream. 


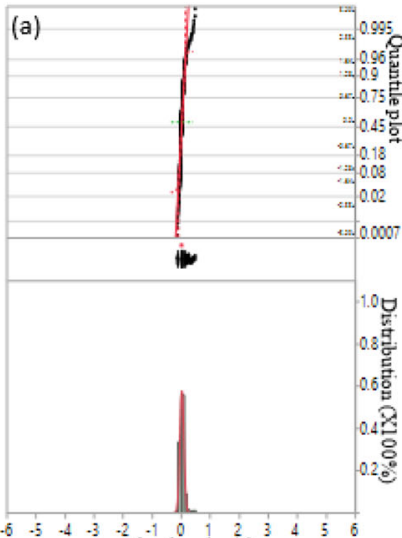

W velocity $(\mathrm{m} / \mathrm{s})$

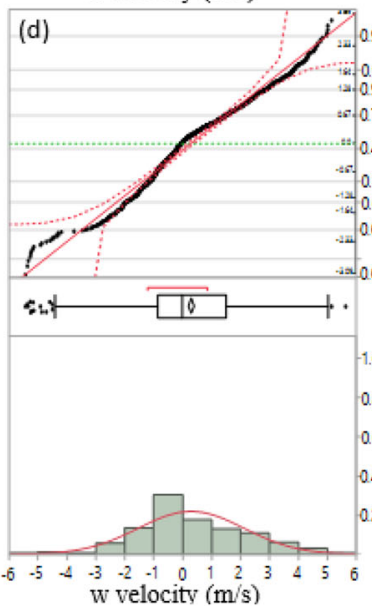

(b)

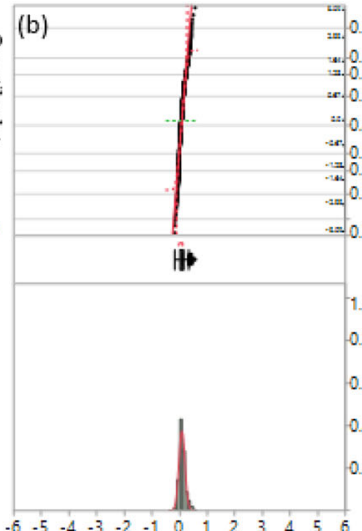

W velocity $(\mathrm{m} / \mathrm{s})$

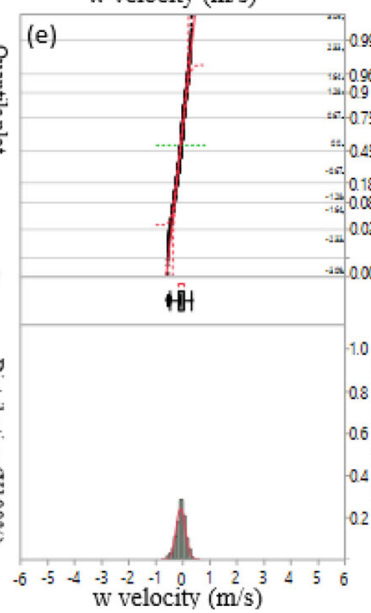

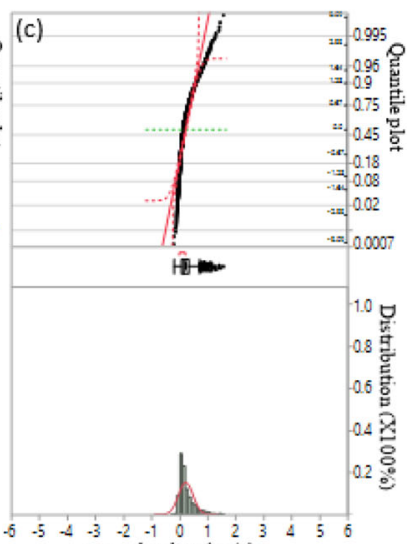

W velocity $(\mathrm{m} / \mathrm{s})$

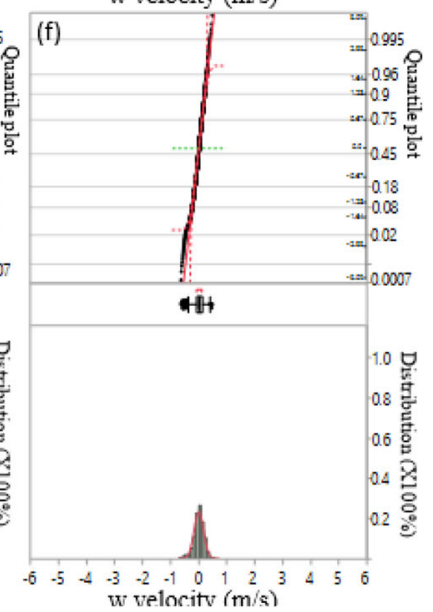

Figure 19. Normal quantile plot, box-and-whisker plots, and distributions of $w$ velocity at different cross sections of the tunnel at t = $900 \mathrm{~s}$ in scenario 2 at: a $430 \mathrm{~m}$ upstream, b $10 \mathrm{~m}$ upstream, c $7 \mathrm{~m}$ upstream, d $10 \mathrm{~m}$ downstream, e $100 \mathrm{~m}$ downstream, 430 downstream. 

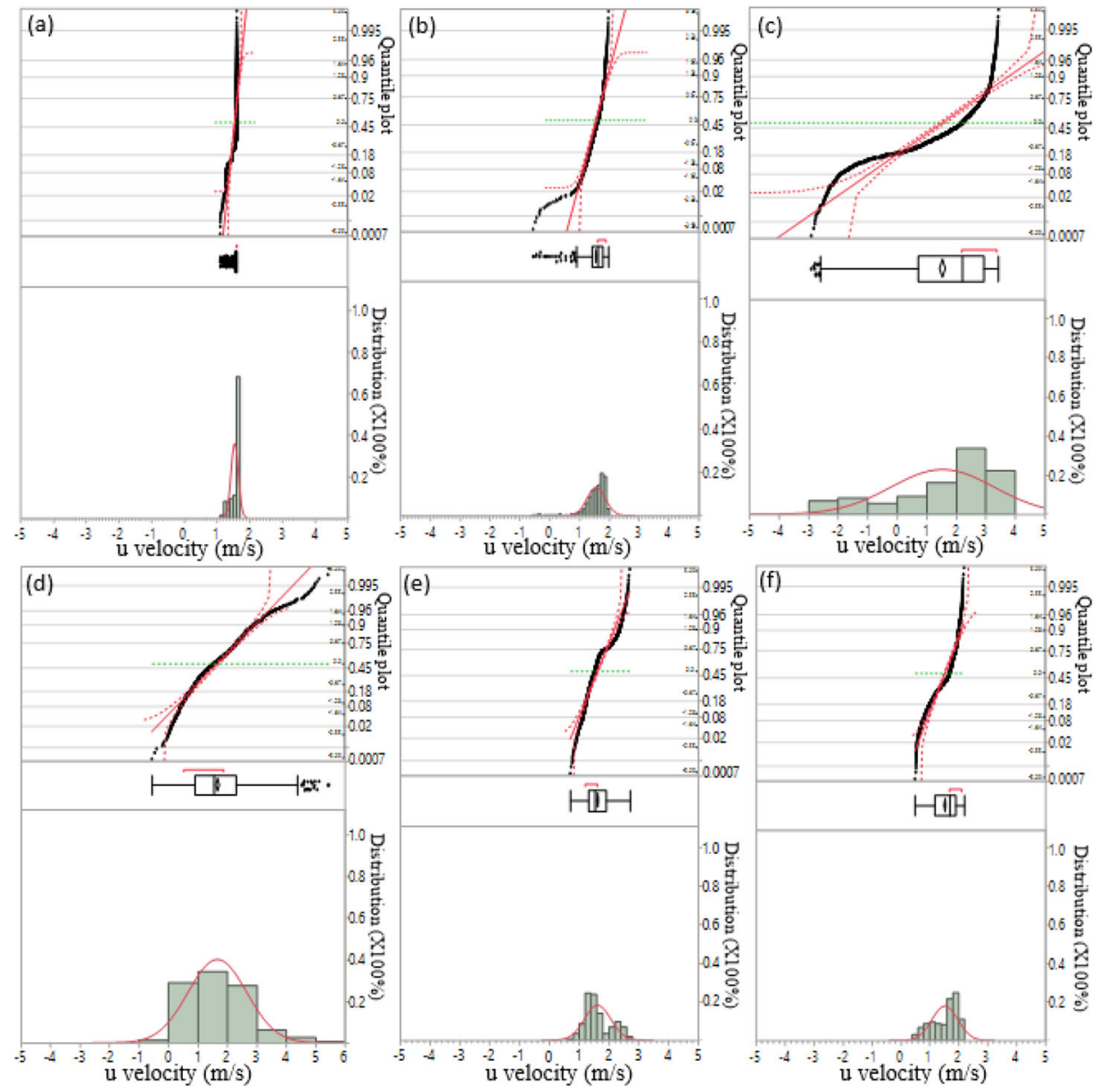

Figure 20. Normal quantile plot, box-and-whisker plots, and distributions of $u$ velocity at different cross sections of the tunnel at $t=900 \mathrm{~s}$ in scenario $3 \mathrm{at:}$ (a) $430 \mathrm{~m}$ upstream, (b) $170 \mathrm{~m}$ upstream, (c) $10 \mathrm{~m}$ upstream, (d) $10 \mathrm{~m}$ downstream, (e) $100 \mathrm{~m}$ downstream, (f) 430 downstream. 

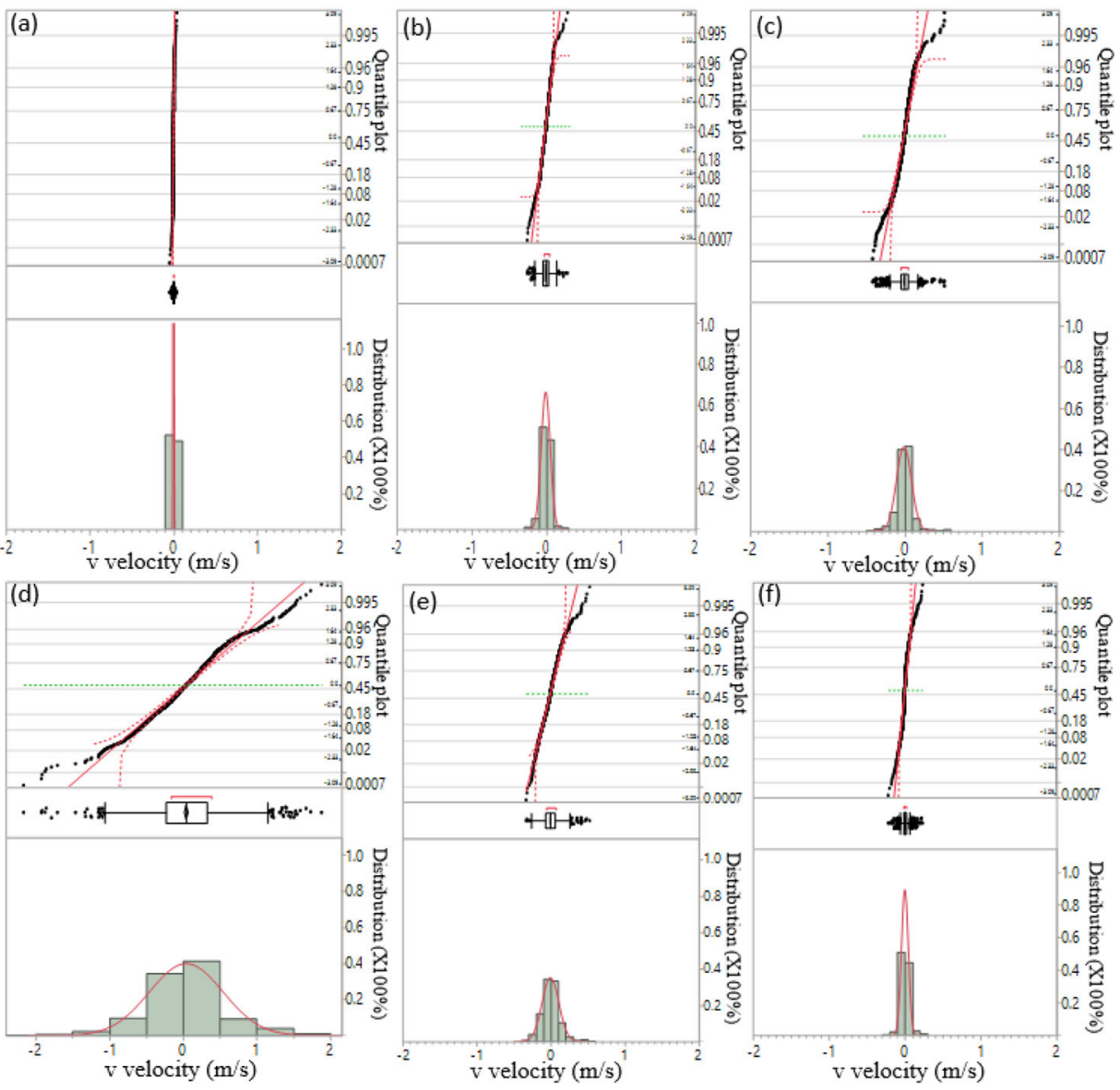

Figure 21. Normal quantile plot, box-and-whisker plots, and distributions of $\mathrm{v}$ velocity at different cross sections of the tunnel at $t=900 \mathrm{~s}$ in scenario 3 at: a $430 \mathrm{~m}$ upstream, b $170 \mathrm{~m}$ upstream, c $10 \mathrm{~m}$ upstream, d $10 \mathrm{~m}$ downstream, e 100 m downstream, f 430 downstream. 

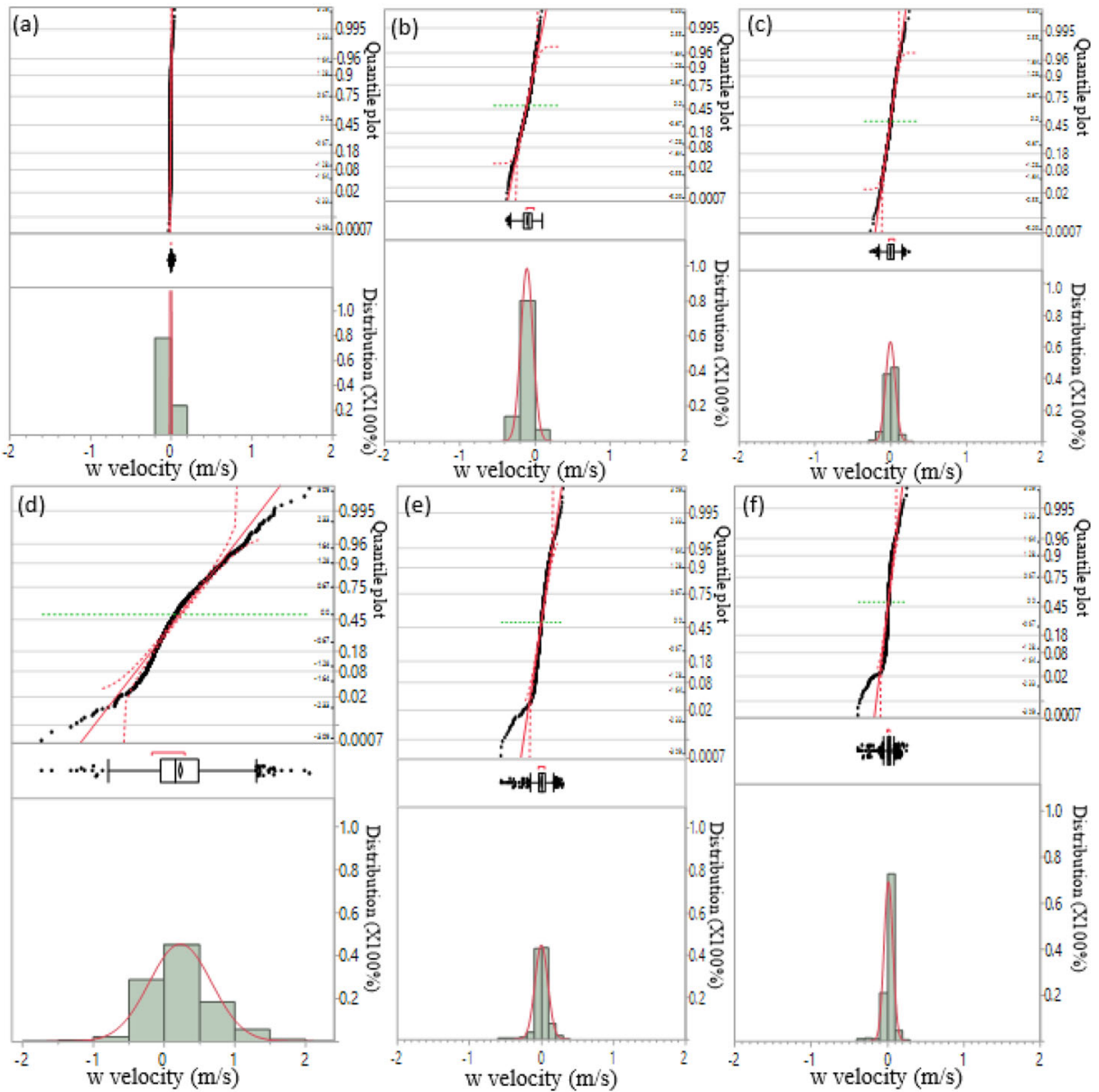

Figure 22. Normal quantile plot, box-and-whisker plots, and distributions of $w$ velocity at different cross sections of the tunnel at $t=900 \mathrm{~s}$ in scenario 3 at: a $430 \mathrm{~m}$ upstream, b $170 \mathrm{~m}$ upstream, c $10 \mathrm{~m}$ upstream, d $10 \mathrm{~m}$ downstream, e $100 \mathrm{~m}$ downstream, 430 downstream.

behavior of the values in scenario 1 . The scenario 3 was considered for investigation of velocity components behavior upstream and downstream of the fire during the upstream transport of smoke scenarios. 

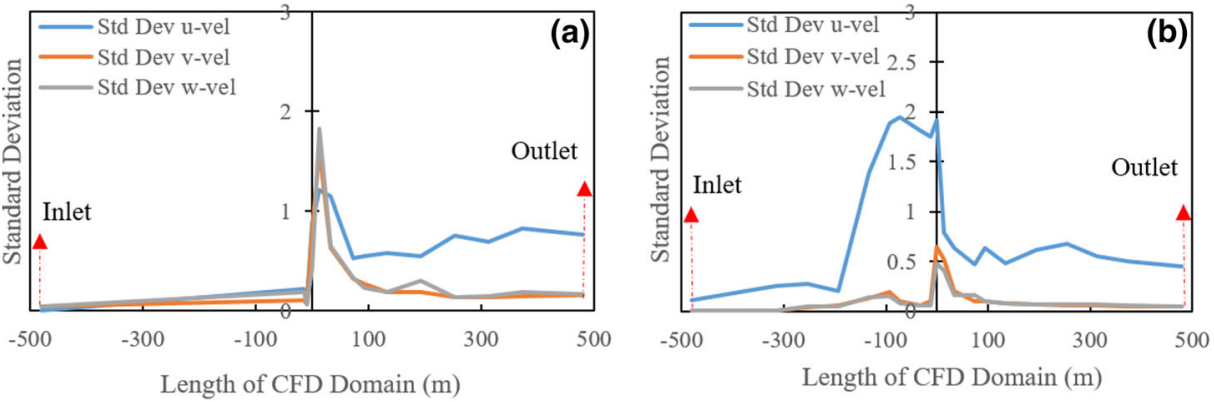

Figure 23. Standard deviation of $u-, v-$, and $w$ velocities at different cross sections of the tunnel for (a) scenario 2 , (b) scenario 3.

Appendix 2: The Mean Velocity and Mean Velocity Components in Scenarios 2 and 3

The mean velocity and mean velocity components in scenario 2 and 3 are shown in Figs. 24 and 25 respectively.
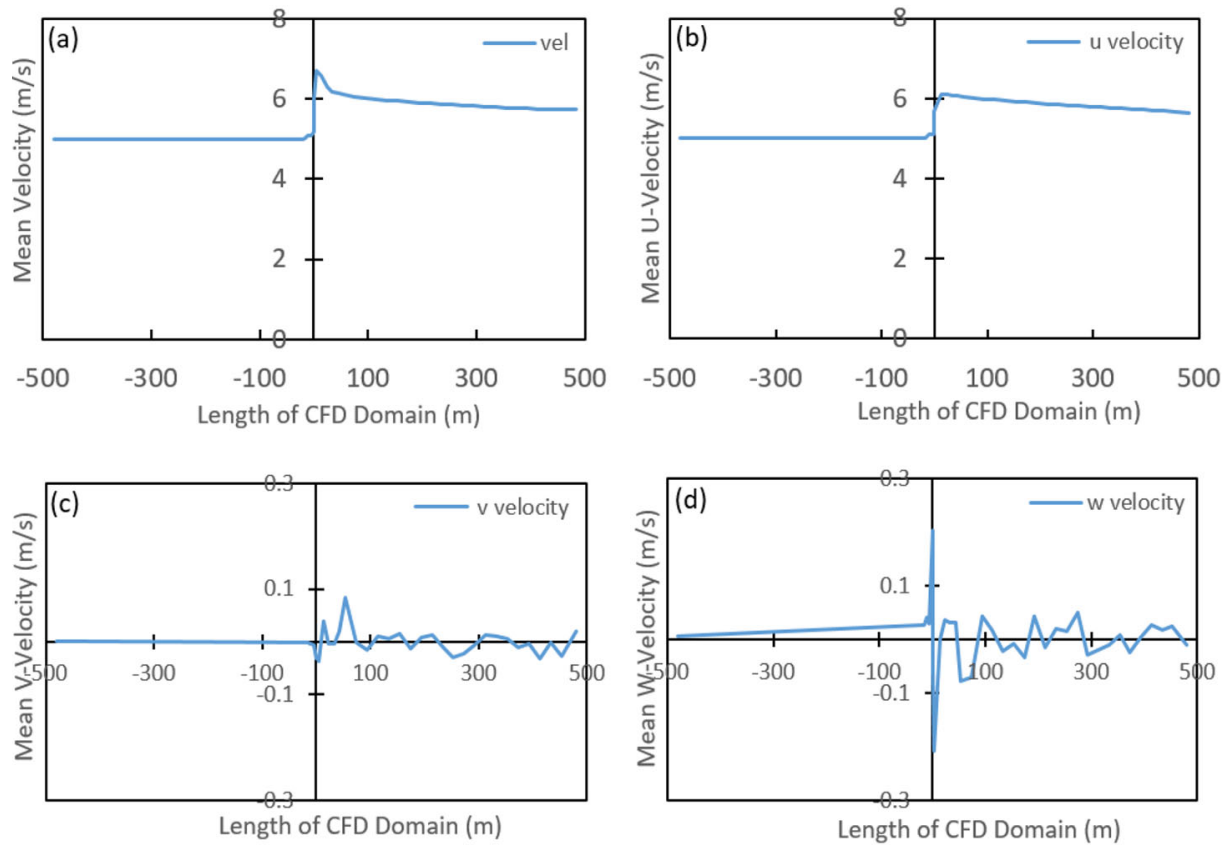

Figure 24. The mean velocity and its components along the height of the tunnel at different cross sections at $t=900 \mathrm{~s}$ in scenario $2 \mathrm{a}$ velocity, b u velocity, c v velocity, d w velocity. 

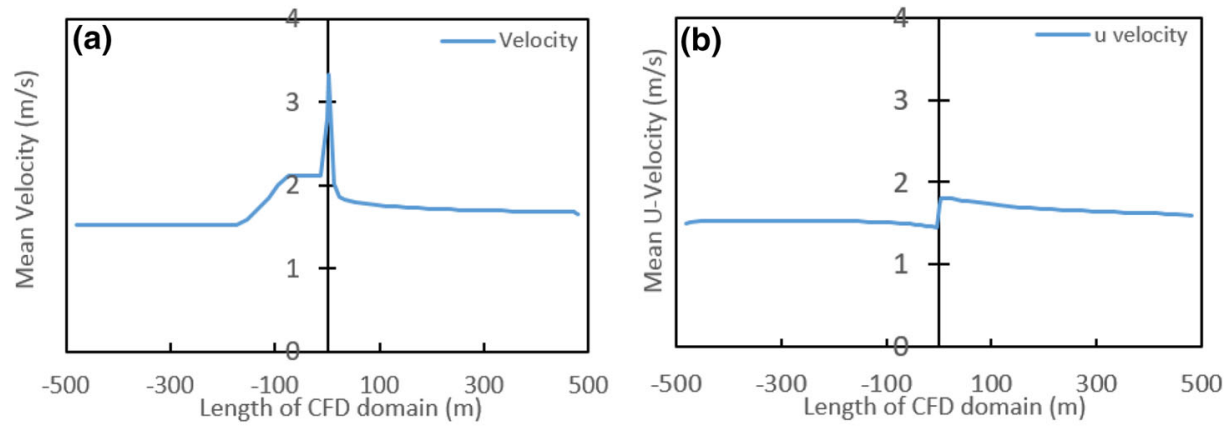

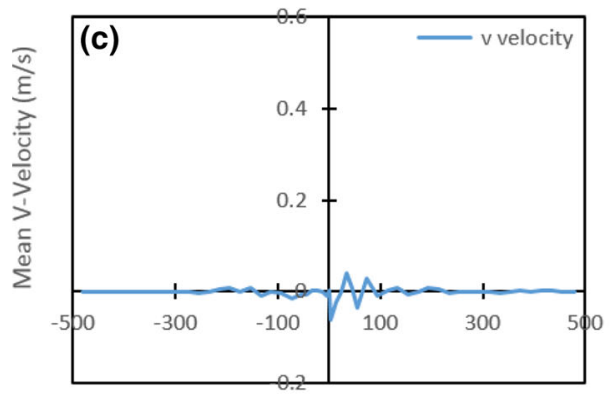

Length of CFD domain ( $\mathrm{m}$ )

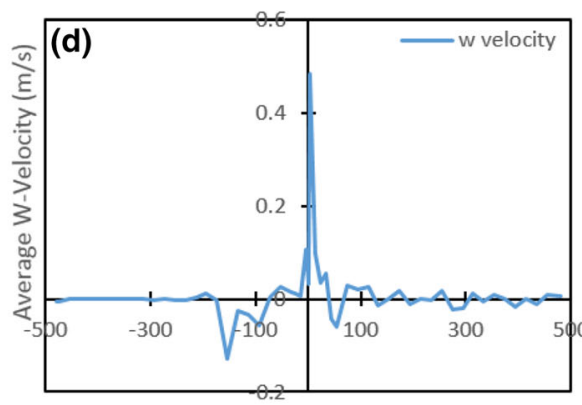

Length of CFD domain ( $m$ )

Figure 25. The mean velocity and its components along the height of the tunnel at different cross sections at $t=900 \mathrm{~s}$ in scenario 3 (a) velocity (b) u velocity (c) v velocity (d) w velocity.

Appendix 3: The Characteristic Points of the Near Fire Filed Region in Scenarios 1, 2, and 3

See Fig. 26.

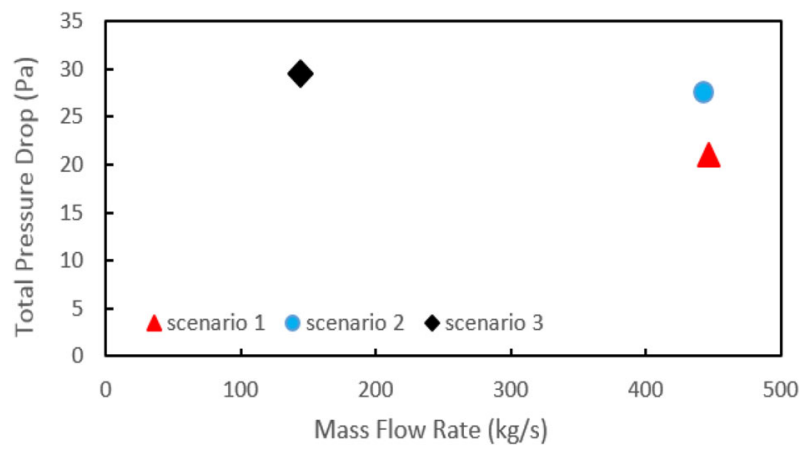

Figure 26. Characteristic points of the near fire field region for all scenarios. 


\section{References}

1. Ang C, Rein G, Peiro J, Harrison R (2016) Simulating longitudinal ventilation flows in long tunnels: comparison of full CFD and multi-scale modelling approaches in FDS6. Tunn Undergr Space Technol 52:119-126

2. Babrauskas V, Peacock RD (1992) Heat release rate: the single most important variable in fire hazard. Fire Saf J 18:255-272

3. Ballesteros-Tajadura R, Santolaria-Morros C, Blanco-Marigorta E (2006) Influence of the slope in the ventilation semi-transversal system of an urban tunnel. Tunn Undergr Space Technol 21:21-28

4. Bamforth B, Chisholm D, Gibbs J, Harrison T (2008) Properties of concrete for use in Eurocode 2: How to optimise the engineering properties of concrete in design to Eurocode 2. A cement and concrete industry publication. ISBN 1904482392, 9781904482390

5. Baum HR, McCaffrey BJ (1989) Fire induced flow field-theory and experiment. In: Fire safety science, Proc. 2nd int. symp. hemisphere, New York, pp 129-148

6. Beard A, Carvel R (2005) The handbook of tunnel fire safety. Thomas Telford Ltd., London

7. Black TJ (1966) Some practical applications of a new theory of wall turbulence. In: Saad MA, Miller JA (eds) Proc. 1966 Heat transfer and fluid mechanics institute, Stanford University Press, Stanford, California, pp 366-386

8. Breuer M, Lakehal D, Rodi W (1996) Flow around a surface mounted cubical obstacle: comparison of LES and RANS-results. In Deville M, Gavrilakis S, Ryming IL (eds) Computation of 3D complex flows. Volume 53 of notes on numerical fluid mechanics. Vieweg Verlag, pp 22-30. https://link.springer.com/chapter/10.1007\%2F978-3-322-8983 $8-8+4$

9. Choi J, Lin CL (2012) Multiscale numerical analysis of airflow in CT-based subject specific breathing human lungs. http://ir.uiowa.edu/etd/2685. Accessed 21 Nov 2012

10. Colella F, Rein G, Borchiellini R, Carvel R, Torero JL, Verda V (2009) Calculation and design of tunnel ventilation systems using a two scale modelling approach. Build Environ J 44:2357-2367

11. Colella F, Rein G, Reszka P, Carvel R, Torero JL (2010) Analysis of the ventilation system in the dartford tunnels using a multiscale modelling approach. TUST 25:423432

12. Colella F, Rein G, Borchiellini R, Torero JL (2011) A novel multiscale methodology for simulating tunnel ventilation flows during fires. Fire Technol 47:221-253

13. Colella F, Rein G, Verda V, Borchiellini R (2011) Multiscale modeling of transient flows from fire and ventilation in long tunnels. Comput Fluids 51:16-29

14. Diego I, Torno S, Toraño J, Menéndez M, Gent M (2011) A practical use of CFD for ventilation of underground works. Tunn Undergr Space Technol 26:189-200

15. Formaggia L, Gerbeau JF, Nobile F, Quarteroni A (2001) On the coupling of 3D and 1D Navier-Stokes equations for flow problems in compliant vessels. Comput Methods Appl Mech Eng 191:561-582

16. Friel GF, Yuan L, Edwards JC, Franks RA (2006) Fire-generated smoke rollback through crosscut from return to intake - experimental and CFD study. In: Mutmansky JM, Ramani RV (eds) Proceedings of the 11th U.S./North American mine ventilation symposium, University Park, Pennsylvania, 5-7 June. Taylor \& Francis Group, London, pp 483-489

17. Frohlich J, Von Terzi D (2008) Hybrid LES/RANS methods for the simulation of turbulent flows. Prog Aerosp Sci 44:349-377 
18. Gannouni S, Ben Maad R (2015) Numerical study of the effect of blockage on critical velocity and backlayering length in longitudinally ventilated tunnel fires. Tunn Undergr Spacee Technol 48:147-155

19. Gutiérrez-Montes G, Sanmiguel-Rojas E, Viedma A, Rein G (2009) Experimental data and numerical modelling of 1.3 and $2.3 \mathrm{MW}$ fires in a $20 \mathrm{~m}$ cubic atrium. Build Environ 44:1827-1839

20. Haghighat A, Luxbacher K, Lattimer B (2016) Simulation of methane fire event at a coal mine working face with consideration of ventilation curtain damage. Trans Soc Min Metall Explor 340:120-126

21. Hassn A, Chiarelli A, Dawson A, Garcia A (2016) Thermal properties of asphalt pavements under dry and wet conditions. Mater Des 91:432-439

22. Heskestad G (2008) SFPE Handbook of Fire Protection Engineering, chapter Fire Plumes, Flame Height and Air Entrainment, 4th edition. National Fire Protection Association, Quincy, pp 7, 25, 144, 146

23. Hinze JO (1975) Turbulence. McGraw-Hill series in mechanical engineering, 2nd edn. New York, McGraw-Hill

24. Hung CJ, Monsees J, Munfah N, Wisniewski J (2009) Technical manual for design and construction of road tunnels - civil elements. Report No. FHWA-NHI-10-034. Federal Highway Administration, Washington, DC. http://www.fhwa.dot.gov/bridge/tunnel/pub s/nhi09010/tunnel_manual.pdf

25. Hurley M, Munguia A (2009) Analysis of FDS thermal detector response prediction capability. J Fire Prot Eng 20:7

26. Hwang CC, Edwards JC (2005) The critical ventilation velocity in tunnel fires - a computer simulation. Fire Saf J 40:213-244

27. Ingason H (2009) Design fire curves for tunnels. Fire Saf J 44:259-265

28. Kunsch JP (2002) Simple model for control of fire gases in a ventilated tunnel. Fire Saf J 37(1):67-81

29. Kuprat AP, Kabilan S, Carson JP, Corley RA, Einstein DRA (2013) Bidirectional coupling procedure applied to multiscale respiratory modeling. J Comput Phys 244:148167

30. Laage LW, Greuer RE, Pomroy WH (1995) MFIRE users' manual. Version 2:20

31. Lee YP, Tsai KC (2012) Effect of vehicular blockage on critical ventilation velocity and tunnel fire behavior in longitudinally ventilated tunnels. Fire Saf J 53:35-42

32. Liang KM, Ma T, Quintiere JG, Rouson D (2003) Application of CFD modeling to room fire growth on walls. NIST GCR 03-849, National Institute of Standards and Technology, Gaithersburg, Maryland, April 2003

33. Ma TG, Quintiere JG (2003) Numerical simulation of axi-symmetric fire plumes: accuracy and limitations. Fire Saf J 38:467-492

34. Maidl B, Thewes M, Maidl U (2014) Handbook of tunnel engineering II, basics and additional services for design and construction. Ernst \& Sohn GmbH \& Co. KG., Berlin

35. McGrattan K, Baum H, Rehm H (1998) Large eddy simulation of smoke movement. Fire Saf J 30:161-178

36. McGrattan K, Hostikka S, McDermott R, Floyd J, Weinschenk C, Overholt K (2014) Fire dynamics simulator technical reference guide volume 1: mathematical model, NIST special publication 1018, sixth edition. FDS Version 6.1.2. Fire Research Division Engineering Laboratory Gaithersburg, Maryland, USA. SVN repository revision: 20596

37. National Cooperative Highway Research Program (NCHRP) Synthesis 415 (2011) Design fires in road tunnels. A synthesis of highway practice. Project 20-05, Topic 41- 
05. ISSN 0547-5570. ISBN 978-0-309-14330-1. Library of Congress Control No. 2010943183

38. National Fire Protection Association (NFPA), "NFPA ${ }^{\circledR} 502$ (2011) Standard for road tunnels, bridges, and other limited access highways, 2011 Edition. ISBN 978161665095-7

39. Nobile F (2009) Coupling strategies for the numerical simulation of blood flow in deformable arteries by 3D and 1D models. Math Comput Model 49:2152-2160

40. Oka Y, Atkinson GT (1995) Control of smoke flow in tunnel fires. Fire Saf J 25(4):305-332

41. Stefopoulos EK, Damigos DG (2007) Design of emergency ventilation system for an underground storage facility. Tunn Undergr Space Technol 22:293-302

42. Tang W, Hu LH, Chen LF (2013) Effect of blockage-fire distance on buoyancy driven back-layering length and critical velocity in a tunnel: an experimental investigation and global correlations. Appl Thermal Eng 60:7-14

43. Tewarson A (1995) SFPE handbook of fire protection engineering, 2nd edn, Section 3, Chapter 4. In: DiNenno P, Beyler C, Custer R, Walton W (eds) National Fire Protection Association

44. Townsend AA (1976) The structure of turbulent shear flow, 2nd edn. Cambridge University Press, New York, NY

45. Van Maele K, Merci B (2008) Application of RANS and LES field simulations to predict the critical ventilation velocity in longitudinally ventilated horizontal tunnels. Fire Saf J 43:598-609

46. Vauquelin $\mathrm{O}, \mathrm{Wu} \mathrm{Y}$ (2006) Influence of tunnel width on longitudinal smoke control. Fire Saf J 41:420-426

47. Vega MG, Diaz KMD, Oro JMF, Tajadura RB, Morros CS (2008) Numerical 3D simulation of a longitudinal ventilation system: memorial tunnel case. Tunn Undergr Space Technol 23(5):539-551

48. Ventsim Visual ${ }^{\mathrm{TM}}$ (2016) Ventsim Visual ${ }^{\mathrm{TM}}$ User Guide, Chasm Consulting, vol 1, Version 4

49. Vermesi I, Rein G, Colella F, Valkvist M, Jomaas G (2017) Reducing the computational requirements for simulating tunnel fires by combining multiscale modelling and multiple processor calculation. Tunn Undergr Space Technol 64:146-153

50. Wang L, Chen Q (2008) Applications of a coupled multizone-CFD model to calculate airflow and contaminant dispersion in built environments for emergency management. HVAC\&R Res 14(6):925-939

51. Wu Y, Bakar MZA (2000) Control of smoke flow in tunnel fires using longitudinal ventilation systems - a study of the critical velocity. Fire Saf J 35:363-390

52. Yuan FD, You SJ (2007) CFD simulation and optimization of the ventilation for subway side-platform. Tunn Undergr Space Technol 22:474-482

53. Yuan L, Mainiero RJ, Rowland JH, Thomas RA, Smith AC (2014) Numerical and experimental study on flame spread over conveyor belts in a large-scale tunnel. J Loss Prev Process Ind 30:55-62 